\title{
GNREL
}

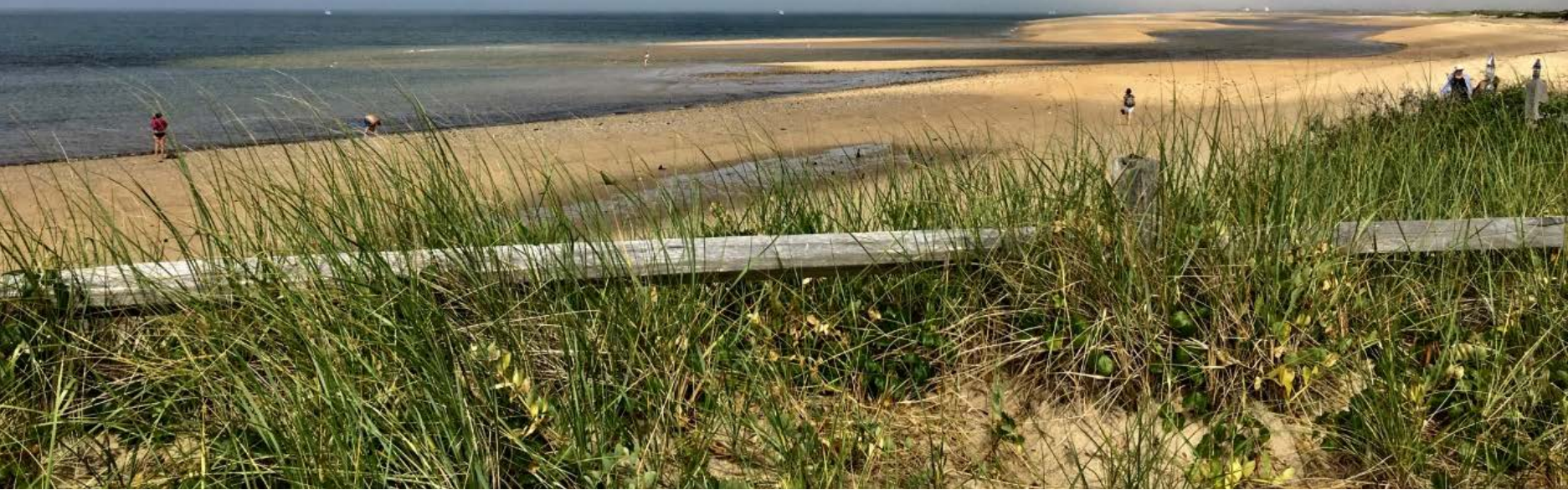

\section{Resilience Assessment: Cape Cod National Seashore}

Eliza Hotchkiss, ${ }^{1}$ Alicen Kandt, ${ }^{1}$ Alison Holm, ${ }^{1}$

Lauren McKean, ${ }^{2}$ and Shawn Norton ${ }^{2}$

1 National Renewable Energy Laboratory

2 National Park Service

NREL is a national laboratory of the U.S. Department of Energy

Office of Energy Efficiency \& Renewable Energy

Operated by the Alliance for Sustainable Energy, LLC

This report is available at no cost from the National Renewable Energy Laboratory (NREL) at www.nrel.gov/publications.
Technical Report

NREL/TP-7A40-79171

November 2021 


\title{
FANEL
}

\section{Resilience Assessment: Cape Cod National Seashore}

\author{
Eliza Hotchkiss, ${ }^{1}$ Alicen Kandt, ${ }^{1}$ Alison Holm, ${ }^{1}$ \\ Lauren McKean, ${ }^{2}$ and Shawn Norton ${ }^{2}$ \\ 1 National Renewable Energy Laboratory \\ 2 National Park Service
}

\section{Suggested Citation}

Hotchkiss, Eliza, Alicen Kandt, Alison Holm, Lauren McKean, and Shawn Norton. 2021. Resilience Assessment: Cape Cod National Seashore. Golden, CO: National Renewable Energy Laboratory. NREL/TP-7A40-79171. https://www.nrel.gov/docs/fy22osti/79171.pdf.

NREL is a national laboratory of the U.S. Department of Energy Office of Energy Efficiency \& Renewable Energy Operated by the Alliance for Sustainable Energy, LLC

This report is available at no cost from the National Renewable Energy Laboratory (NREL) at www.nrel.gov/publications.

Contract No. DE-AC36-08GO28308
Technical Report

NREL/TP-7A40-79171

November 2021

National Renewable Energy Laboratory 15013 Denver West Parkway Golden, CO 80401

303-275-3000 • www.nrel.gov 


\section{NOTICE}

This work was authored in part by the National Renewable Energy Laboratory, operated by Alliance for Sustainable Energy, LLC, for the U.S. Department of Energy (DOE) under Contract No. DE-AC36-08G028308. Funding provided by the National Park Service. The views expressed herein do not necessarily represent the views of the DOE or the U.S. Government.

This report is available at no cost from the National Renewable Energy Laboratory (NREL) at www.nrel.gov/publications.

U.S. Department of Energy (DOE) reports produced after 1991 and a growing number of pre-1991 documents are available free via www.OSTI.gov.

Cover Photo National Park Service

NREL prints on paper that contains recycled content. 


\section{Acknowledgements}

The National Renewable Energy Laboratory team thanks the National Park Service (NPS) for the opportunity to perform this resilience assessment for the Cape Cod National Seashore (CCNS) in Massachusetts. In particular, the assessment team is grateful to NPS Headquarter staff, CCNS staff, and Tristan Jilson at Barnstable County for providing data and input into this analysis.

The assessment team also thanks Pragadeesh Meenakumar and Kathleen Krah, from NREL, who were contributors to this analysis by conducting the REopt analysis and writing the associated appendix. 


\section{Executive Summary}

Since 2016, the National Park Service (NPS) has been assessing the vulnerability of coastal parks to coastal hazards and identifying opportunities to enhance operational resilience across parks. Coastal parks are affected by sea level rise, storm surge, and coastal flooding, which have caused operational interruptions. NPS partnered with the National Renewable Energy Laboratory (NREL) in 2019 to develop resilience plans at specific high-risk coastal parks. The purpose of this project was to further asses the vulnerability of coastal park infrastructure specific to energy, communications, transportation, and water systems, for improved future operational resilience at those parks and to consider applications for lessons learned across the NPS portfolio.

Leveraging existing vulnerability assessments and past renewable energy analyses, NREL completed resilience plans at specific high-risk pilot parks to serve as a foundation for more comprehensive assessments and resilience planning activities. This assessment is a summary of the efforts at Cape Cod National Seashore (CCNS). It outlines the methodology used and the results of the analysis, with the intention of serving as a case study for other parks interested in replicating the process.

The resilience assessment methodology employed at CCNS — that could be adapted at other parks - was designed around four primary steps: compiling and assessing baseline information; identifying and scoring hazards, threats, and vulnerabilities; analyzing risks based on potential impact and likelihood; and developing and prioritizing mitigation actions and next steps. A risk matrix was developed to map relationships between hazards, threats, and vulnerabilities and provide a risk score for each hazard- or threat-vulnerability combination. The risk matrix is a visual representation of site risk designed to foster deeper discussion with park staff and highlight high-priority vulnerabilities to target with mitigation solutions.

The risk matrix was used to understand the areas of greatest concern at CCNS and brainstorm potential solutions. Solutions incorporate a range of implementation levels (e.g., easy to difficult), a range of costs to implement (e.g., lower cost to higher capital costs), and address risks through mitigation solutions or holistic resilience solutions. Solutions that simultaneously address multiple related vulnerabilities, those that are easy to implement, and those that address risks that are likely to occur and significantly impact CCNS's infrastructure or operations are included. 


\section{List of Acronyms}

API

ARLC

AST

CCNS

DOE

ESPC

FEMA

HQ

MVP

NPS

NREL

PMIS

PV

TOC

UST

WAN
Asset Priority Index

Atlantic Research \& Learning Center

aboveground oil tank

Cape Cod National Seashore

U.S. Department of Energy

energy savings performance contract

Federal Emergency Management Agency

headquarters

Municipal Vulnerability Preparedness

National Park Service

National Renewable Energy Laboratory

Project Management Information System

photovoltaic

Telecommunications Operations Center

underground oil tank

Wide Area Network 


\section{Table of Contents}

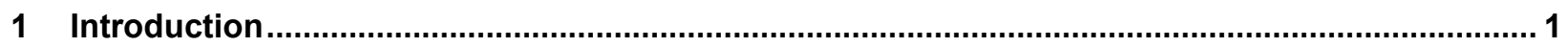

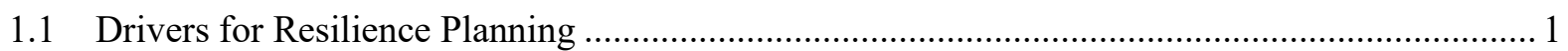

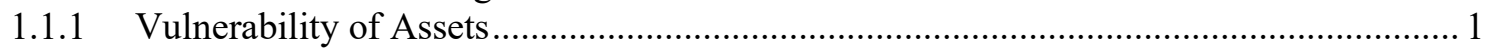

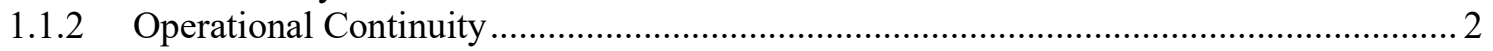

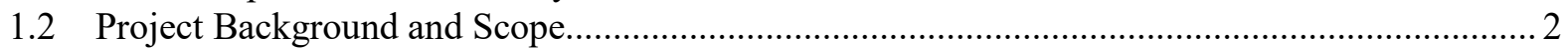

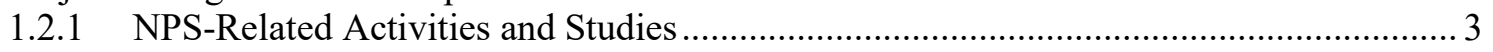

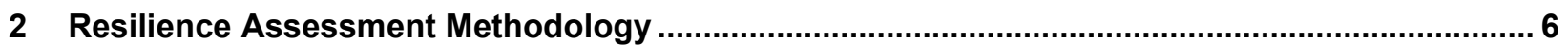

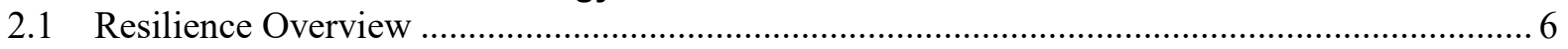

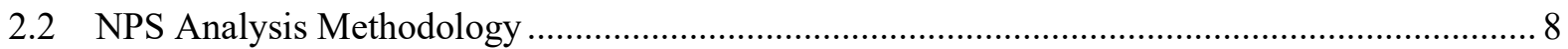

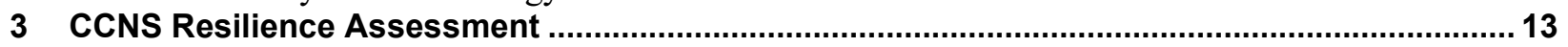

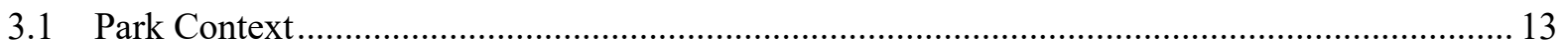

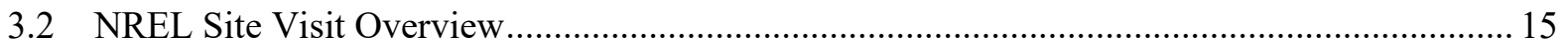

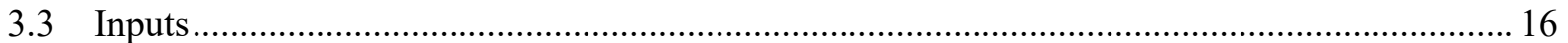

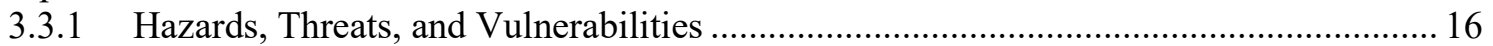

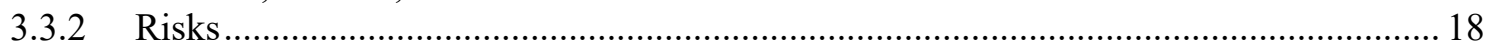

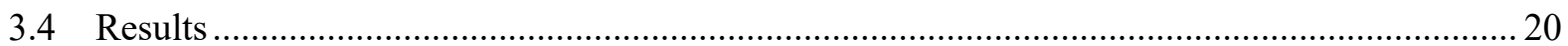

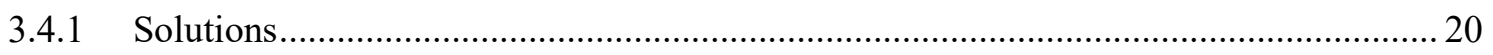

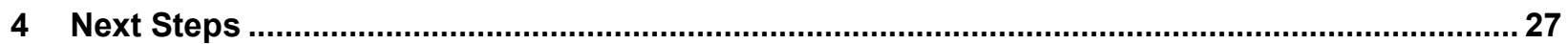

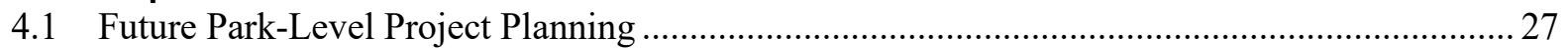

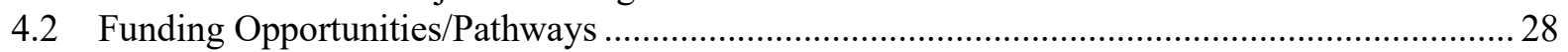

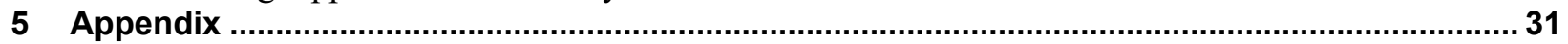

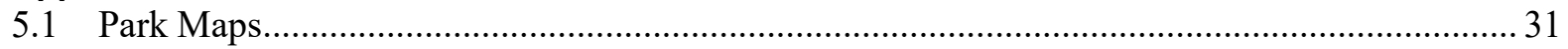

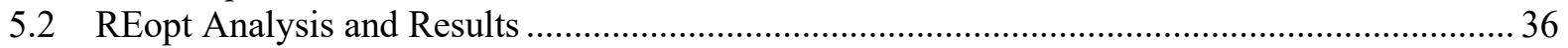

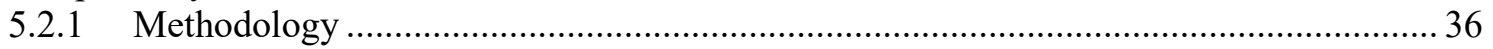

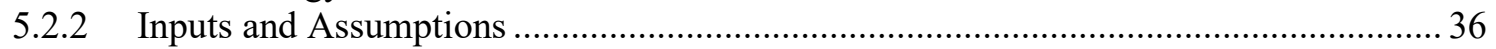

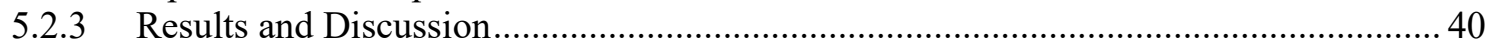

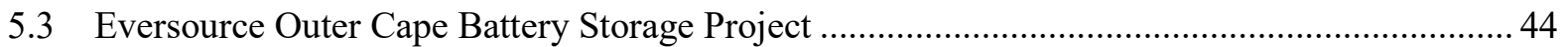

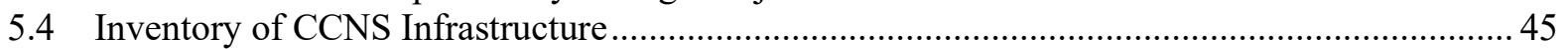

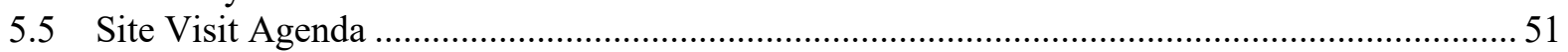

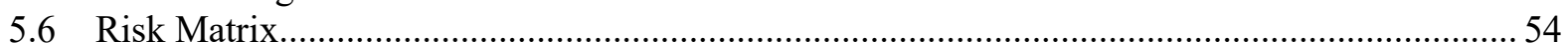

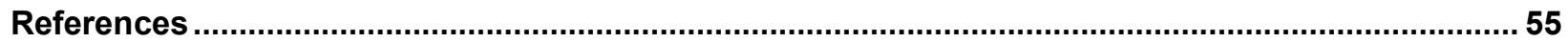




\section{List of Figures}

Figure 1. Sea level trends for the United States based on Zervas (2009), for all available data through 2015

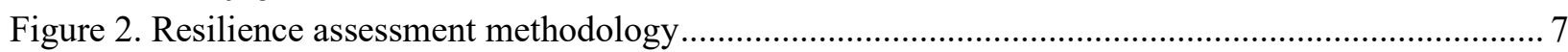

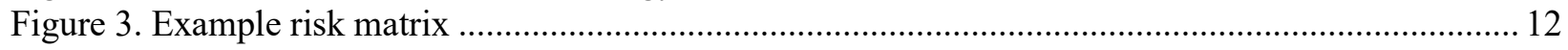

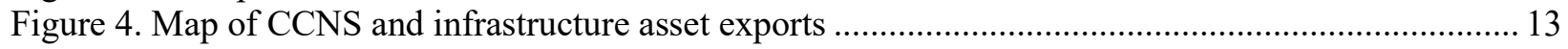

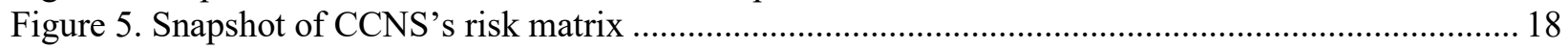

Figure 6. Map of Provincetown, Massachusetts, and infrastructure asset exposure .............................. 20

Figure 7. Map of Eastham, Massachusetts, and infrastructure asset exposure ...................................... 32

Figure 8. Map of Provincetown, Massachusetts, and infrastructure asset exposure .................................. 33

Figure 9. Map of Truro, Massachusetts, and infrastructure asset exposure ............................................. 34

Figure 10. Map of Wellfleet, Massachusetts, and infrastructure asset exposure ..................................... 35

Figure 11. Monthly electric consumption across all 78 buildings, provided by NPS .............................. 37

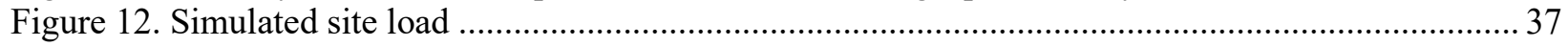

Figure 13. Simulated site load, showing CCNS HQ load as critical load during grid outages (red circles)

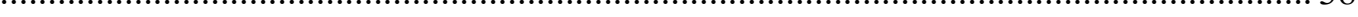

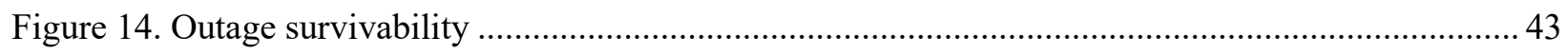

\section{List of Tables}

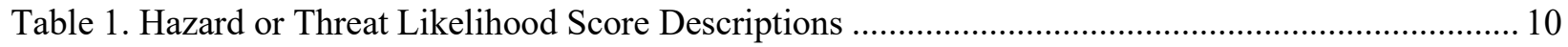

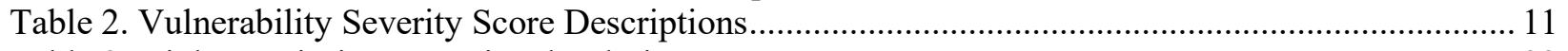

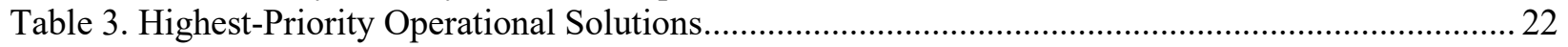

Table 4. Highest-Priority Facility Solutions by Cost and PMIS Project Funding Request Number .......... 26

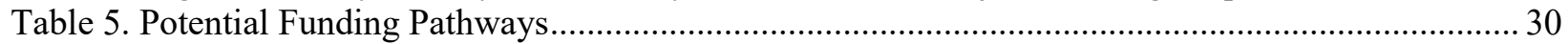

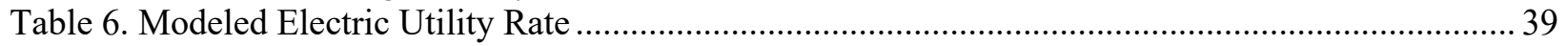

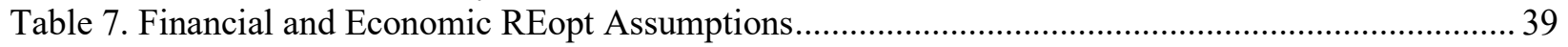

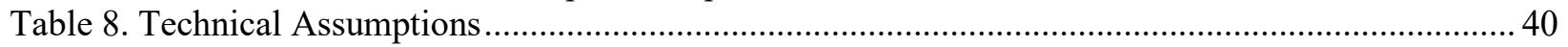

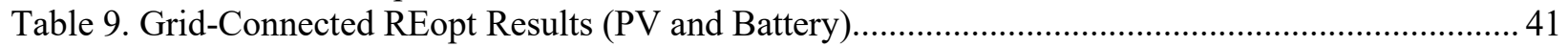

Table 10. Resilience REopt Results (PV, Battery, and Generator) ......................................................... 42 


\section{Introduction}

The National Park Service (NPS) was founded in 1916 to consolidate management of America's federal parklands under one agency and today manages 85 million acres across all U.S. states, the District of Columbia, American Samoa, Guam, Puerto Rico, and the Virgin Islands (NPS 2021). NPS manages 422 areas, which include national parks, monuments, battlefields, military parks, historical parks, historic sites, lakeshores, seashores, recreation areas, scenic rivers and trails, and the White House (NPS 2021). The management of treasured natural lands and resources, along with historical and cultural resources, poses unique challenges for protecting and preserving these assets.

The NPS protects natural resources, cultural resources, and facilities in over 120 coastal parks and over 12,000 miles of shoreline experiencing effects from climate change-including sea level rise along ocean coastlines, changing storm patterns, melting permafrost, saltwater intrusion, ocean acidification, inundation during coastal storms, reduced water levels in the Great Lakes, and the impacts of changing temperature and precipitation regimes (NPS 2016). In 2016, NPS launched a project to assess the level of vulnerability of these coastal parks are to coastal hazards and to identify opportunities to enhance operational resilience across parks. Coastal parks are affected by sea level rise, storm surge, and coastal flooding, which cause operational interruptions.

\subsection{Drivers for Resilience Planning}

Resilience planning is important to the NPS because disruptions to park operations can have significant consequences to natural and cultural resources as well as built infrastructure; impacts to infrastructure often result in avoidable costs. Additionally, parks are a key component of local economies for communities. Vulnerabilities, operational continuity, and funding to address deferred maintenance backlogs are important drivers for resilience planning.
Why Focus on Coastal Parks?
Approximately $40 \%$ of the nation's population lives in counties on a coastline. NPS manages 120 coastal parks, and national parks are a key economic driver for local communities through tourism and jobs.

\subsubsection{Vulnerability of Assets}

Park asset vulnerabilities can include any number of infrastructure and organizational challenges. that are left unaddressed. The NPS system is built on the nation's backbone of aging infrastructure. Many of the facilities within parks were built by the Civilian Conservation Corps, which means they are historic structures and need to be maintained to prevent decay. The location of the nation's parks in remote areas or along coastlines exposes the parks to hazards such as wildfires and flooding. When assets are not maintained in the face of a potential hazard or threat, the vulnerabilities are more likely to be exposed. For example, infrastructure that has not been hardened or sited to account for potential flooding due to increased storm surges along a coastline will be more likely to be weakened or disrupted during a flooding event. Those disruptions have an impact on park operations. Reducing asset vulnerability through mitigation measures is essential to the viability of park operations. 


\subsubsection{Operational Continuity}

Continuity of operations is a common driver for resilience planning. Parks can use continuity of operations to support resilience planning efforts, because there are similarities in processes from readiness and preparedness, activation and relocation involving plans and procedures, and reconstituting operations at an alternate facility or returning to normal operating conditions. Ensuring the missions and essential functions at parks can continue in the face of multiple hazards and threats will enhance NPS's and individual parks' abilities to protect and preserve public lands, historic assets, and economic stability.

\subsection{Project Background and Scope}

This report summarizes the collaborative resilience assessment process NREL undertook with Cape Cod National Seashore (CCNS) and outcomes specific to the park. The results and methodology used can serve as a case study for other parks interested in replicating the process. Leveraging existing vulnerability assessments and renewable energy analyses, NREL completed resilience plans at specific high-risk pilot parks to serve as a foundation for more comprehensive assessments and resilience planning activities.

Since 2016, NPS has completed vulnerability assessments at 40 of the most vulnerable coastal parks to determine how multiple coastal hazards may impact transportation and structural infrastructure over a 35-year planning horizon. Building on these efforts, the NPS partnered with the National Renewable Energy Laboratory (NREL) in 2019 to develop resilience plans at highrisk parks, focusing on energy, communications, transportation, and water systems and related infrastructure. Resilience planning is context-specific, and resilience solutions are implemented locally, but the process undertaken with individual parks can be replicated to inform future resilience planning efforts and decision-making across NPS areas and other federal land management agencies. The intended project outputs are twofold: (1) park-specific resilience plans and solutions for three coastal parks that can be included in strategic investment plans for operational resilience; and (2) a generalized approach to resilience planning that incorporates NPS-specific priorities, data, and considerations that other parks can follow to develop targeted resilience plans for their sites.

Resilience planning efforts can vary in size and scope and are most productive when they are iterative and multistakeholder endeavors. NREL conducted site assessments at the pilot parks to gather data related to energy, water, communications systems, and transportation assets not previously analyzed (such as fleet composition and transportation fuels). This included a site visit, interviews with park staff, and ongoing collaboration with key park and NPS staff. Data gathered from the project inform a broader, holistic analysis of hazards, threats, and vulnerabilities, and a detailed risk assessment encompassing broader infrastructure components, specifically energy (including transportation energy needs), communication, and water systems at pilot parks. The analysis examines the opportunities for mitigation and investment by utilizing geospatial information system data, analytics, and industry standards for assessing risk. Considerations include a geospatial risk assessment of the park's primary mission, risk to the park staff and visitor populations, emergency operations risk, risk to the nearby population and risk to infrastructure in the park and within near proximity of the park due to a utility (including energy, water, and wastewater) outage. Interdependencies between communications, 
cybersecurity, transportation, water, and energy are explored to highlight areas of high vulnerability to prioritize resilience measures and investment strategies.

\subsubsection{NPS-Related Activities and Studies}

Existing studies were used to support the resilience assessment at the park. These studies include previous vulnerability and resilience-related studies, along with renewable energy and transportation studies. These were provided by the park and are summarized below.

\section{Vulnerability and Resilience-Related Studies}

In 2016 NPS launched a project to determine how vulnerable coastal parks are to sea level change and flooding from coastal storms. Rising sea levels coupled with storm events like Hurricanes Katrina and Sandy, which increase storm surge, are endangering natural and cultural resources. These conditions may require changes to coastal infrastructure to maintain operational resilience. Outcomes of this effort included the development of the Coastal Adaptation Strategies Handbook 2016, as well as the initiation of vulnerability assessments at 40 coastal parks (Beavers, Babson, and Schupp 2016).

These vulnerability assessments leverage the Coastal Hazards and Climate Change Asset Vulnerability Assessment Protocol, developed by NPS and Western Carolina University's Program for the Study of Developed Shorelines (NPS 2020). This protocol is used to assess the vulnerability of transportation and building infrastructure to multiple coastal hazards and climate change factors (i.e., erosion, flooding, storm surge, sea-level rise, and historical flooding) over a 35-year planning horizon (to 2050). The overall goal is to standardize the methodology and data used in park vulnerability assessments, allowing park managers to compare the vulnerability of coastal transportation and structural assets across local, regional, and national levels.

The assessments examined the vulnerability of structures, such as buildings, and transportation assets, but did not examine the vulnerability of infrastructure related to energy, communication, or water systems. Results provide insight into vulnerabilities at a subset of high-risk parks and serve as a valuable foundation for more comprehensive vulnerability assessments and resilience planning activities. 


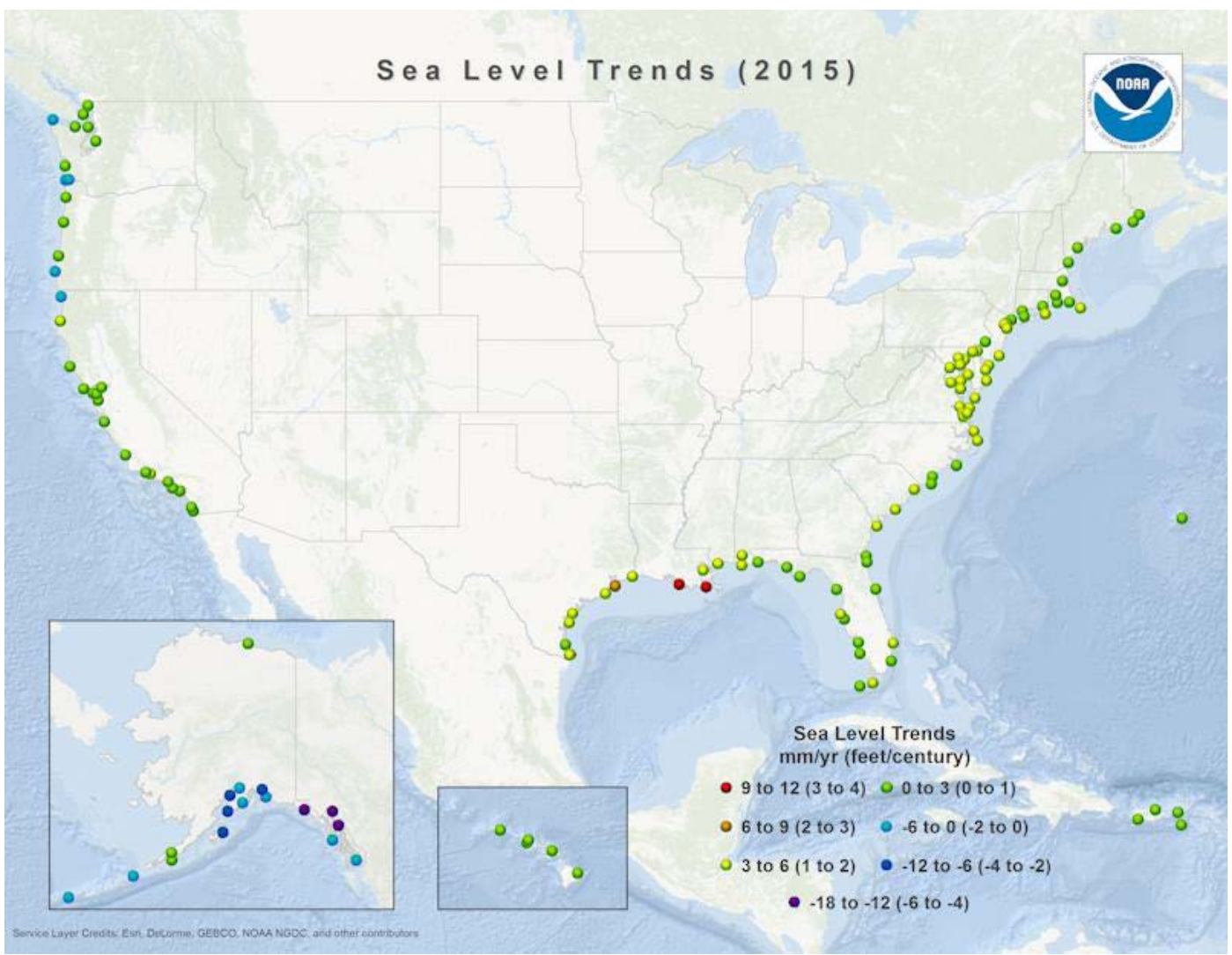

Figure 1. Sea level trends for the United States based on Zervas (2009), for all available data through 2015

Source: National Park Service (2018)

Note: Each dot represents the location of a long-term (>30 years) tide gauge station. Green dots represent stations that are experiencing the average global rate of sea level change. Stations depicted by yellow to red dots are experiencing greater than the global average (primarily driven by regional subsidence) and blue to purple dots are stations experiencing less than the global average (due to isostatic rebound or other tectonically-driven factors).

In 2018, a report entitled Sea Level Rise and Storm Surge Projections for the National Park Service was published by the University of Colorado in partnership with NPS and provided sea level rise and storm surge projections for coastal area national parks, using information from the United Nations Intergovernmental Panel on Climate Change and storm surge scenarios from National Oceanic and Atmospheric Administration models. The analysis provides sea level rise projections for 118 park units and storm surge projections for 79 of those parks (Caffrey, Beavers, and Hawkins Hoffman 2018).

\section{Renewable Energy and Transportation-Related Studies}

In 2014, NPS worked with NREL and the Federal Energy Management Program to conduct renewable energy analyses, using the REopt ${ }^{\mathrm{TM}}$ tool, at 320 parks. Site visits and additional analyses have been conducted at parks with high renewable energy potential, and cost-effective projects have been pursued via appropriations, third-party financing, and grant opportunities. 
NREL has also been supporting NPS with alternative-fuel vehicle and infrastructure projects via the Clean Cities National Parks Initiative (DOE). These efforts have supported over 32 projects at 29 NPS units and resulted in an annual reduction of 70,000 gallons of petroleum used. 


\section{Resilience Assessment Methodology}

The resilience assessment methodology used for CCNS was a proven methodology developed by NREL and modified to incorporate other activities within the NPS.

\subsection{Resilience Overview}

Resilience refers to "the ability to anticipate, prepare for, and adapt to changing conditions and withstand, respond to, and recover rapidly from disruptions through adaptable and holistic planning and technical solutions" (DOE). Resilience planning is conducted by analyzing the risks to a site based on the hazards and threats most likely to occur and vulnerabilities. Hazards and threats are "anything that can damage, destroy, or disrupt" a site or asset. Hazards and threats are external, typically outside of the site or agency's immediate control and can be characterized as natural (e.g., hurricanes, earthquakes, wildfire), technological (e.g., infrastructure failure, poor workmanship, or design), or human-caused (e.g., accidents, cyberattacks, political upheaval). Vulnerabilities are "weaknesses within infrastructure, systems, or processes, and/or systems" that, when exposed to a hazard or threat, can result in damage or disruption (Stout et al. 2019). Vulnerabilities impact the degree of susceptibility to various hazards or threats. Example vulnerabilities include single point of access to the site, single overhead electrical line, or staff lacking necessary training. While hazards and threats may not be within human control, measures can be put into place to correct potential vulnerabilities. These measures are designed to reduce the impacts of vulnerabilities exposed by a hazard or threat. The consequences associated with the vulnerabilities being exposed as a result of a hazard or threat being realized is one way to frame the impacts associated with risks.

Hazards, threats, and vulnerabilities are site-specific and need to be assessed for each individual park to understand the current resilience baseline. Addressing the highest priority areas first will help enhance resilience.

At a high level, the resilience assessment methodology employed at CCNS - which could be adapted at other parks - was designed around four primary steps: compiling and assessing baseline information; identifying and scoring hazards, threats, and vulnerabilities; analyzing risks based on potential impact and likelihood; and then developing and prioritizing mitigation actions and next steps. As depicted in Figure 2, to be effective this process should be revisited to allow for updates to the various components, such as changing missions, shifting vulnerabilities, and evolving hazards and threats.
The resilience assessment methodology used for this analysis is derived from NREL's Resilience Roadmap and Energy Resilience Assessment Methodology. These documents contain additional background context and guidance that may be useful to park planners. 


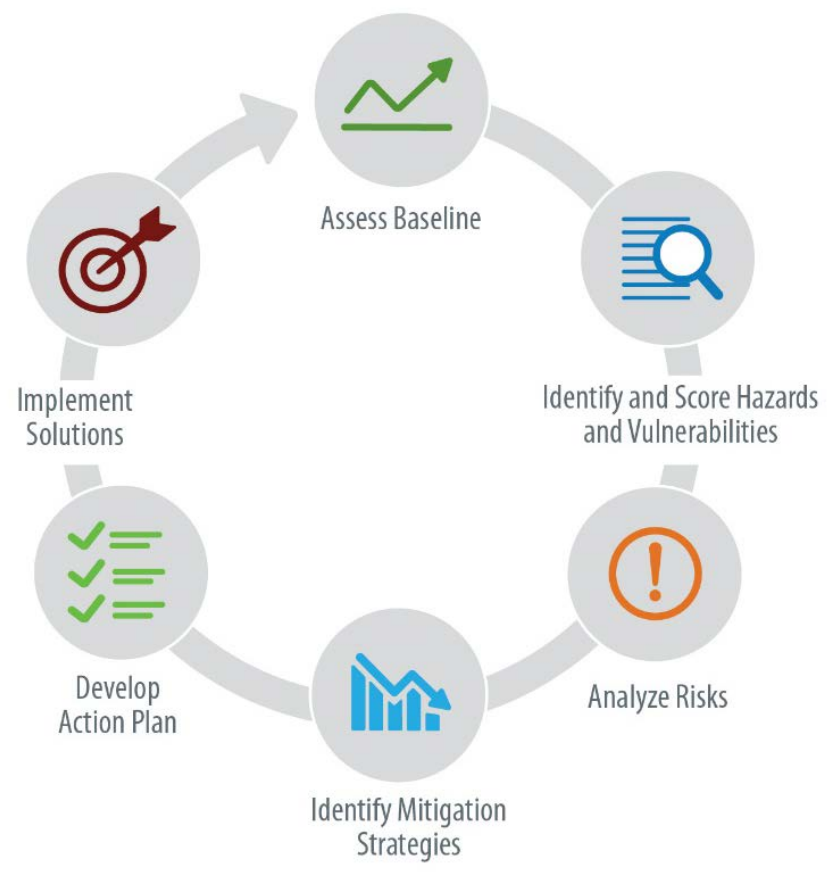

Figure 2. Resilience assessment methodology

Source: Anderson et al. 2019

The baseline assessment establishes an understanding of current conditions, with a focus on an agency or organization's mission, existing mitigation efforts, and environmental and sociopolitical contexts. Acknowledging the uncertainties, variability, and fluidity of the various components of a resilience assessment, the risk and mitigation scoring methodologies used here were intentionally built to be flexible. The method utilized is a relatively qualitative and subjective approach to estimating risk and mitigation, using stakeholder input obtained through a site visit and subsequent remote communication. A more detailed approach would involve computing specific quantitative probabilities for hazards and threats and detailed cost-based consequences for vulnerabilities. However, assessment teams should be mindful of the costbenefit trade-offs of using specific probabilities and cost-based consequences. In this analysis, the methodology used presents a holistic and multisectoral approach to understand the greatest risks and identify resilience measures that can be used to inform decision-making.

Finally, this assessment uses a framework of hazards, threats, and vulnerabilities to identify resilience challenges and, eventually, opportunities for investment and action. A vulnerability is internal to the system and/or within the site's control. These could be weaknesses within infrastructure, systems, or processes. On the other hand, hazards and threats are external and can be anything that will damage, destroy, or disrupt the site or critical asset. When taken together, the analysis will highlight where weaknesses in an existing system can be negatively exploited by a hazard or threat that could create a crisis or disaster for the park.

Resilience planning is typically most effective when it can be integrated alongside existing processes and plans. In adapting and tailoring this overarching resilience assessment approach to CCNS, NREL and NPS and park staff identified several substeps that leverage existing park planning resources. These considerations are discussed in more detail in the next section. 


\subsection{NPS Analysis Methodology}

In applying the resilience assessment methodology outlined in the previous section to CCNSand with an eye toward developing a process that could easily be applied at other parks - NREL, the NPS Washington Office, and CCNS staff sought to leverage existing processes for documenting and prioritizing funding for park infrastructure maintenance as part of the resilience assessment. This section maps NPS-specific considerations and data sources onto the generalized resilience assessment methodology outlined in the previous section.

\section{Assess Baseline}

- Compile List of Park Facilities and Assets: At the outset of the resilience assessment, CCNS discovered that information on park facilities, transportation networks, and communication assets existed in several different places. As a first step, park staff collected and consolidated all information related to park infrastructure and assets. Next, park staff and NREL created a spreadsheet containing all park facilities or assets in a single sheet. The spreadsheet initially included two key pieces of information: the facility or asset name and the source of that information (i.e., which document the park facility or asset was pulled from).

- Consolidate Asset Priority Index (API) and Exposure Rankings by Park Facility or Asset: After the list of park facilities and assets was compiled, NREL cross-referenced and added columns for park data on API and exposure rankings associated with each facility or asset. These two pieces of information were used to determine a categorical criticality ranking (high, medium, low), which is later used to determine the facilities or assets that may be most vulnerable and that should be prioritized for mitigation measures. API data was obtained from the park. ${ }^{1}$ Exposure ranking data-indicators of asset exposure to coastal hazards and sea level rise - was obtained from the park based on a 2018 exposure analysis conducted by NPS and the Program for the Study of Developed Shorelines at Western Carolina University. ${ }^{2}$ API and exposure rankings were selected as metrics to determine park criticality rankings because: (1) API is an existing indicator of relative importance of infrastructure components within a park; (2) exposure analyses and resulting exposure rankings data are available for a subset of coastal parks with a plan to develop rankings for all parks; and (3) both API and exposure rankings are standardized across NPS, and they are well-defined processes that parks already follow. Not all facilities or assets had associated API or exposure rankings; those facilities or assets were flagged for manual evaluation of criticality (see next step).

- Determine Park Criticality Ranking: The next step in the process was to multiply the API and exposure rankings to yield a numerical park criticality ranking. The numerical criticality ranking was then converted into a categorical ranking — high, medium, low —as a first approximation at relative criticality across park assets and facilities.

- Review List and Manually Adjust Criticality Rankings: The final step in assessing baseline information for the park was to review the spreadsheet and manually adjust criticality rankings where appropriate. Some assets, for example, did not have an API or

\footnotetext{
${ }^{1}$ For more information on API, see https://irma.nps.gov/DataStore/DownloadFile/591358.

${ }^{2}$ For more information on exposure studies, see

https:/www.nps.gov/subjects/climatechange/vulnerabilityandadaptation.htm.
} 
exposure ranking, including several communications systems, transportation assets, or important regional facilities. In some cases, these assets were determined to be critical by park staff (communications systems, for example) and were categorized as "high" criticality.

\section{Consider Hazards, Threats, and Vulnerabilities}

- Identify Hazards and Threats: Hazards and threats can be identified through existing assessments and stakeholder interviews. In this case, CCNS collected and documented known hazards and threats based on existing exposure analyses, past studies, and institutional knowledge. NREL led a half-day planning workshop during which CCNS staff discussed and identified hazards and threats at the park. Results from that discussion are listed in Section 4: CCNS Resilience Assessment.

- Group or Nest Hazards and Threats: After the full spectrum of potential hazards and threats was identified, CCNS and NREL staff reviewed the list for completeness and redundancy. Related hazards and threats were grouped and collapsed into the highestlevel categorization. For example, CCNS identified both invasive species and Southern Pine bark beetle infestation as potential hazards. These were combined and collapsed under "invasive species" to capture the overarching hazard, but staff retained notes on the specific subcases to come back to during solution development and prioritization. Conducting this step of grouping or nesting hazards and threats by meaningful distinction becomes helpful later in assigning likelihood scores and analyzing risk.

- Identify Vulnerabilities: Similar to the process for identifying hazards and threats, CCNS collected and documented known vulnerabilities based on existing exposure analyses, past studies, and institutional knowledge. Interviews with park staff are invaluable when identifying vulnerabilities. Specific to the NPS system, API and existing exposure rankings are useful in determining vulnerability associated with individual park facilities or assets.

- Group or Nest Vulnerabilities: After identifying potential vulnerabilities, CCNS and NREL staff reviewed the list for completeness and specificity. Because mitigation measures will be closely tied to the vulnerabilities identified, understanding the root causes of vulnerabilities is important. For example, "staffing issues" might be identified as a vulnerability but is not particularly informative in identifying a resilience gap. "Lack of sufficient staff during a disaster event" or "frequent staff turnover resulting in limited institutional knowledge" provide more specificity, which will help when identifying solutions later.

\section{Analyze Risk}

- Develop a Risk Matrix: After hazards, threats, and vulnerabilities were identified and grouped, the next step was to develop a risk matrix that maps the relationships between hazards, threats, and vulnerabilities and provides a risk score for each hazard- or threatvulnerability combination. Threats are listed on one axis and vulnerabilities on the other to create a visual representation of prioritized vulnerability-hazard or -threat combinations and foster deeper discussion with park staff about targeted solutions.

- Score Hazard or Threat Likelihood and Vulnerability Impact: Next, each hazard, threat, and vulnerability identified and included in the risk matrix is assigned a hazard or threat likelihood or vulnerability severity score. Scores were determined according to the 
threshold descriptions in Table 1 and Table 2 below. Scores can be presented either categorically (e.g., high, medium, low) or numerically (e.g., on a scale of 1-9). Numerical scores were used for the CCNS analysis.

Table 1. Hazard or Threat Likelihood Score Descriptions

\begin{tabular}{|c|c|c|}
\hline \multicolumn{2}{|c|}{$\begin{array}{l}\text { Hazard or Threat Likelihood } \\
\text { Scores }\end{array}$} & \multirow[t]{2}{*}{ Threshold Descriptions } \\
\hline Categorical & Numerical & \\
\hline High & 9 & $\begin{array}{l}\text { Almost certain to occur. Historic and frequent } \\
\text { occurrences. }\end{array}$ \\
\hline Medium-High & 7 & More likely to occur than not. \\
\hline Medium & 5 & May occur. \\
\hline Low-Medium & 3 & $\begin{array}{l}\text { Slightly elevated level of occurrence. Possible, but } \\
\text { more likely not to occur. }\end{array}$ \\
\hline Low & 1 & $\begin{array}{l}\text { Very low probability occurrence. An event has the } \\
\text { potential to occur but is still very rare. }\end{array}$ \\
\hline
\end{tabular}


Table 2. Vulnerability Severity Score Descriptions

\begin{tabular}{|c|c|c|}
\hline \multicolumn{2}{|c|}{$\begin{array}{l}\text { Vulnerability Severity } \\
\text { Score }\end{array}$} & \multirow[t]{2}{*}{ Threshold Descriptions } \\
\hline Categorical & Numerical & \\
\hline High & 9 & $\begin{array}{l}\text { Highest magnitude of consequence. Entire power system would be impacted. } \\
\text { Extreme financial impacts would exist. }\end{array}$ \\
\hline $\begin{array}{l}\text { Medium- } \\
\text { High }\end{array}$ & 7 & $\begin{array}{l}\text { Significant consequences to the organization. Majority of population served would } \\
\text { be impacted. Staff tasks would be switched to emergency/critical operations. } \\
\text { Significant financial impacts would exist. }\end{array}$ \\
\hline Medium & 5 & $\begin{array}{l}\text { Medium magnitude of consequence. The organization would be somewhat affected. } \\
\text { Specific systems or functions would be substantially interrupted, but not all. } \\
\text { Financial impacts would be expected to change budgeting plans or require } \\
\text { reallocation of funds. }\end{array}$ \\
\hline $\begin{array}{l}\text { Low- } \\
\text { Medium }\end{array}$ & 3 & $\begin{array}{l}\text { Slightly elevated consequence to the organization. The power sector may need to } \\
\text { temporarily transition operations to backup systems to resolve failure. Limited } \\
\text { financial impacts may become apparent. }\end{array}$ \\
\hline Low & 1 & $\begin{array}{l}\text { Lowest magnitude (or severity) of consequence to the organization. The power } \\
\text { sector would experience little to no effects, or an in-place backup system would } \\
\text { resolve the failure. }\end{array}$ \\
\hline
\end{tabular}

- Determine whether a relationship exists between hazards or threats and vulnerabilities (yes/no): The next step is to determine which hazards or threats are related to which vulnerabilities. Not all hazards, threats, and vulnerabilities will necessarily intersect; not every threat will expose every vulnerability. For example, in CCNS's case, shark incidents were identified as a likely hazard, but shark incidents do not have a relationship with aging facility infrastructure. Unrelated hazards or threats and vulnerabilities will not yield a useful risk score.

- Calculate risk score based on threat/vulnerability scores: After relationships between hazards or threats and vulnerabilities are determined, a risk score can be calculated for each related hazard- or threat-hazard combinations by multiplying the hazard or threat likelihood and vulnerability severity scores for each hazard- or threat-vulnerability combination. The result will be a heat map of where risk is highest and lowest, as shown in Figure 2. 


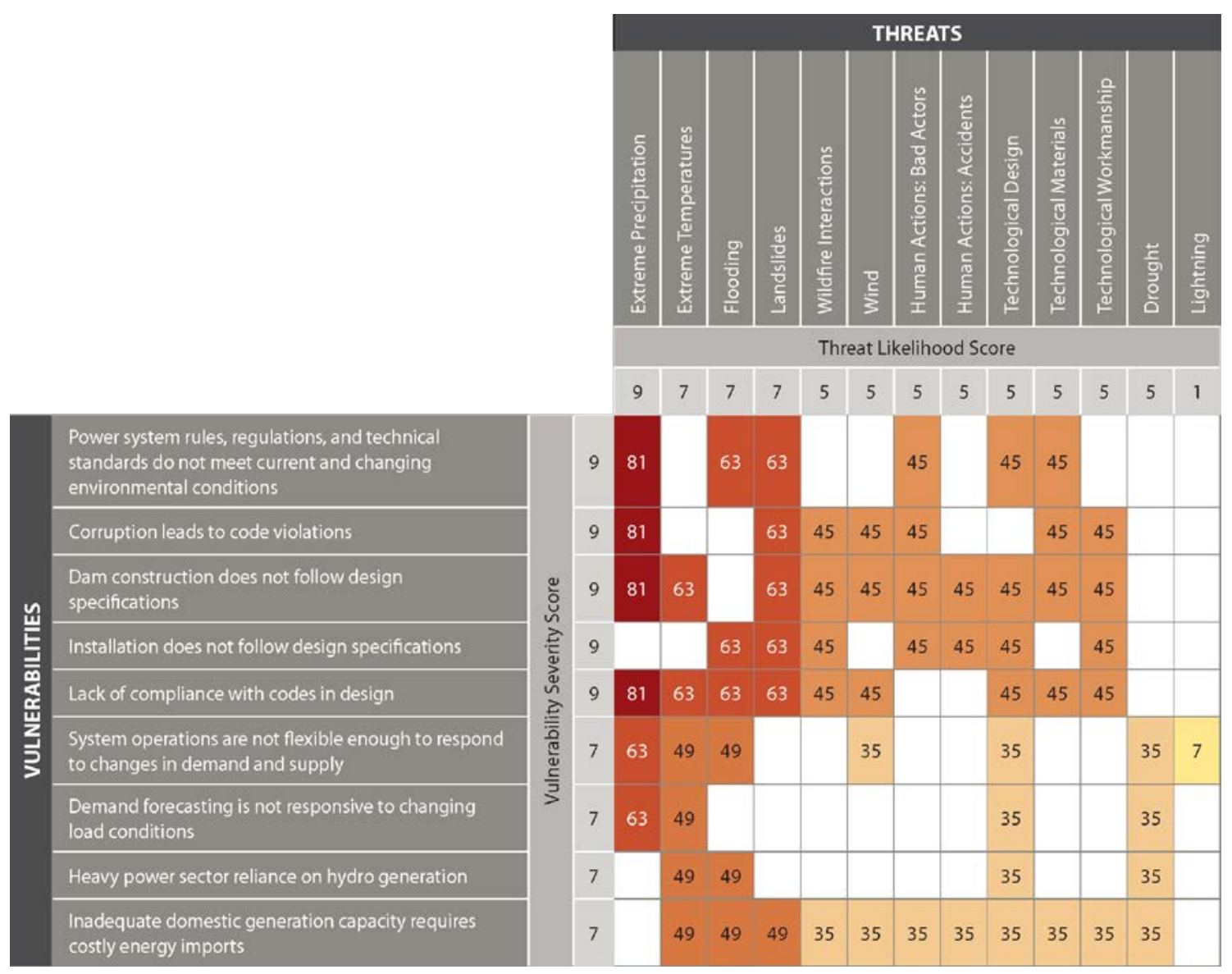

Figure 3. Example risk matrix

Source: Stout et al. 2019

- Cross-Reference and Review Results: Using the data in the previous steps, next review the results for any potential discrepancies between the matrix outputs and other data sources or studies, identify any new gaps arising, or examples of double-counting, and adjust the matrix as needed.

\section{Prioritize Mitigation Actions}

- Develop solutions:

$\circ$ Identify solutions and determine where those solutions apply to hazards, threats, and vulnerabilities so solutions can be prioritized and grouped.

- Solutions can be developed based on a threshold score, depending on the total number of hazards, threats, and vulnerabilities they address (e.g., prioritization of developing solutions to risks with a score of 70 and above captures the majority of the high-impact and high-frequency events). 


\section{CCNS Resilience Assessment}

This section provides park-specific context, including background information related to the workshop held with park staff and the data and inputs provided by CCNS.

\subsection{Park Context}

CCNS was founded in 1961 and has approximately four million visitors per year, although there has been some recent variability in annual visitation attributed to the COVID pandemic. The six major public beaches are the primary draw for visitors, and the park protects and maintains a diverse ecosystem and important historical assets. Located on the hook-shaped peninsula east of Hyannis, Massachusetts, the park shares infrastructure and boundaries with six Outer Cape towns along Route 6. A map of CCNS, with a denotation of infrastructure asset exposure, is shown in Figure 4. Similar maps of each municipality are included in Appendix 5.1.

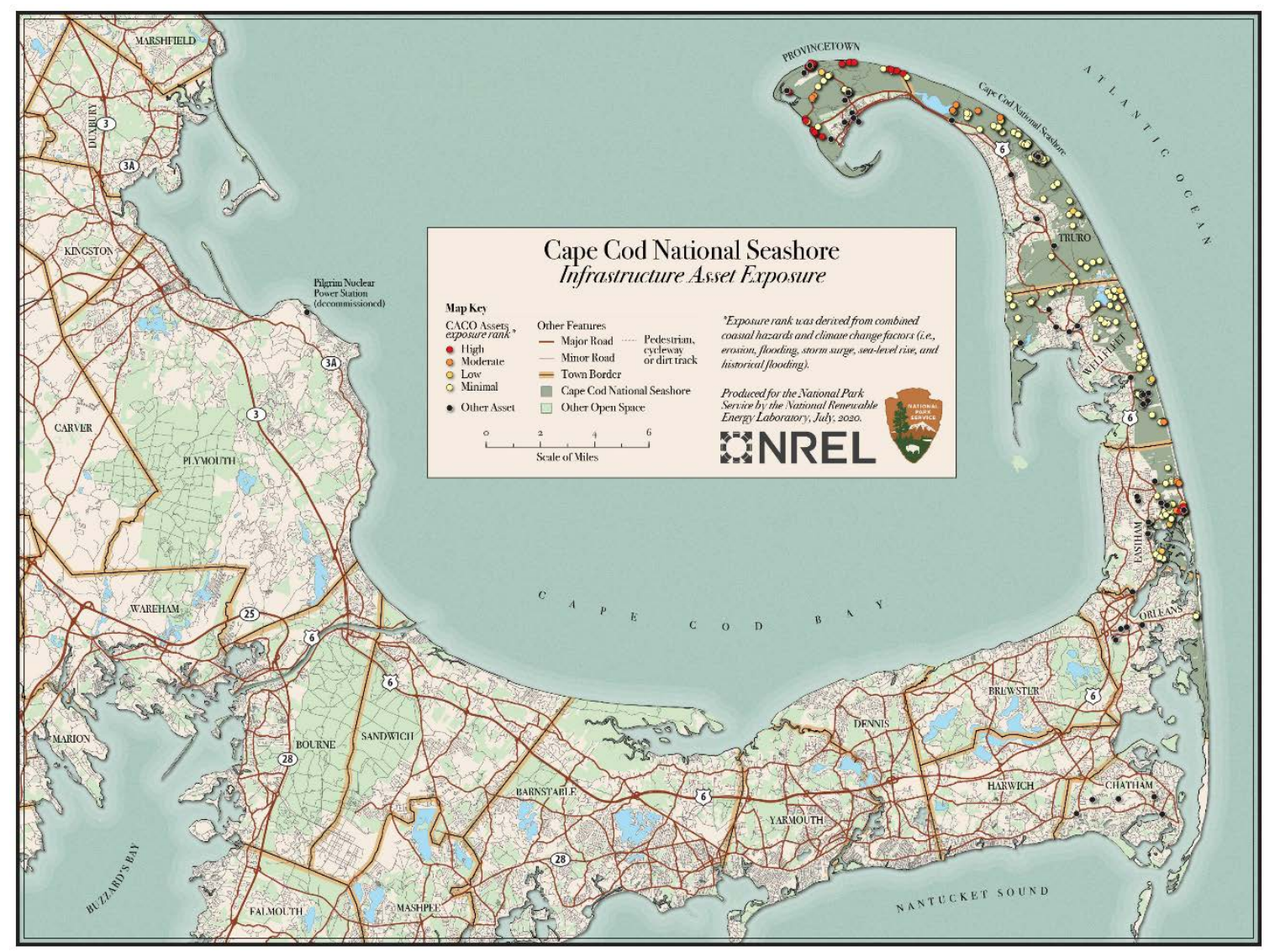

Figure 4. Map of CCNS and infrastructure asset exports

Image by Billy Roberts, NREL

CCNS has a robust planning and management staff and program. The park was assembled from 2,000 parcels of land, adding some complexities to planning, as well as infrastructure management and partnerships. CCNS's Green Team coordinates environmental, climate, and resilience efforts across the site and has representation from each operational department. Although not a comprehensive list, CCNS staff have recently completed or participated in the following planning efforts, which help inform resilience activities: 
- Developed Climate Change Hazards Summary Report for Facility Investment Planning (2021)

- Completed Government Shutdown Incident Action Plan (2019)

- Participated in Municipal Vulnerability Planning (2019)

- Completed and routinely update Park Hurricane Plan (2019)

- Small park-town team participated in Northeast Region Climate Adaptation and Communication Workshop (2018) Foundation Document (2018)

- Performed Park Energy Audits (2010 and 2016)

- Western Carolina University conducted a park facility vulnerability assessment for park roads and buildings (2018)

- Resource Stewardship Strategy (2021)

- Completed Climate-Friendly Parks Action Plan (2011).

CCNS relies on public and local utilities and infrastructure. The primary energy infrastructure is owned by Eversource, the park's serving utility; the main power generation plant is located along a single primary transmission line. Eversource is implementing the Outer Cape Community Battery Project, a utility-scale lithium-ion battery planned for Provincetown, Massachusetts. The project will mitigate the need to build 13 miles of additional overhead wires, some of which are located on CCNS land. CCNS holds a deed restriction on the property where the battery will be constructed on town land within the boundary of the park and consented to the use. More information on the Outer Cape Community Battery Project is provided in Appendix 5.3.

Propane heat, natural gas, oil and electric heat, and solar energy systems are used at various locations in the park. Potable water is provided predominantly by individual supply wells, but also Marconi water tower and Provincetown and Eastham municipal water lines, while septic systems provide the majority of the wastewater treatment and disposal. There are roughly 60 water systems and 70 septic systems contained within the park boundaries.

Additionally, information and communications systems for park operations comprise five primary Local Area Networks, radio systems, emergency 911 call boxes at the six beaches, and satellite phones.

The transportation network within the park features 36 miles of trails, 24 miles of road, and 2.5 miles of boardwalk. A helipad and municipal airport are also located within the park boundary, as are two electric vehicle charging stations for fleet vehicles. The regional ferries and airport operated out of Provincetown are important to both operations and access to the park by visitors, as is Route 6 . The park is equipped with ground vehicles (100), heavy equipment (30), boats, trailers, canoes, kayaks, and ground transportation vehicles to support operations.

The park is also responsible for maintaining over 300 facilities, including ranger headquarters (2), visitors centers (2), laboratories (3), ${ }^{3}$ occupied houses (80), historic structures (44), parking spaces $(2,800)$, maintenance buildings (2), automotive shops (2), amphitheaters (2), and restroom buildings (13). An inventory of park infrastructure and assets is provided in Appendix 5.4.

\footnotetext{
${ }^{3}$ Includes the BioLab, BioLab addition, and the ARLC laboratory.
} 
Facilities that are deemed important to park operations include:

- Salt Pond Visitor Center, Eastham

- Nauset Ranger Station, Eastham

- Headquarters, Wellfleet

- Fire Cache, Wellfleet

- South District Maintenance, Wellfleet

- Biolab, Truro

- Race Point Ranger Station, Provincetown

- Province Lands Visitor Center, Provincetown

- North District Maintenance, Provincetown.

The unique layout of CCNS, along with its mission, make the partnerships between the park and the surrounding communities and service providers, as well as management of the assets and infrastructure, a complex and important aspect of the CCNS.

CCNS is interconnected with the surrounding community; resilience planning activities at both the park and broader community level will be most effective when coordinated. While CCNS staff have embarked on climate resilience planning, the neighboring towns have prepared Municipal Vulnerability Preparedness (MVP) plans as part of the state of Massachusetts's MVP grant program. The Towns of Provincetown, Eastham, Chatham, Orleans, and a joint effort of the Town of Wellfleet and Truro, have resulted in MVPs that express similar concerns to CCNS about the natural hazards that pose a threat to Cape Cod. Their MVPs also bring attention to similar infrastructure concerns, such as Route 6 and the area's ability to provide potable water to the public in emergency circumstances.

The main areas of concern that these reports focus on include transportation, public amenities/facilities, ecosystems, and vulnerable populations within each municipality. In their MVPs, the towns stress the importance of planning for their vulnerable populations and enhancing their communication/outreach efforts with the public, the county, and other communities, and other agencies. By focusing on specific aspects of their respective municipality, these MVPs highlight preparedness planning issues that are complementary to the park's resilience planning effort.

The communities are also responsible for routinely developing a local Hazard Mitigation Plan. The town drafts the document with input from staff and residents, and then it is reviewed and approved by the Massachusetts Emergency Management Agency and the Federal Emergency Management Agency (FEMA). Once their plan is approved, the towns are eligible for FEMA's Hazard Mitigation Assistance program. To remain eligible for the Hazard Mitigation Assistance program, Hazard Mitigation Plans must be updated and resubmitted to FEMA every 5 years. There are several purposes of the plans: to reduce damages resulting from natural hazards by implementing policies and actions to mitigate, reduce, or eliminate long-term risk to human life and property; and to develop an outreach strategy to prepare the community for potential impacts and for recovery from storm events.

\subsection{NREL Site Visit Overview}

As part of the resilience assessment for CCNS, two NREL staff traveled to CCNS on November 20-21, 2019, to conduct a site visit and interview park staff to collect resilience-related 
information. The team conducted tours at all CCNS facility locations and met with a variety of park managers and specialists to understand existing baseline conditions and operations. Stakeholder interviews were unstructured to allow for themes to emerge naturally. In advance of the site visit, CCNS staff provided data on energy, water, wastewater, transportation, and communications systems, which informed the general direction of the stakeholder interviews.

The site visit consisted of a kickoff meeting with CCNS' Green Team, a site tour, informal interviews with individual staff members, and a half-day interactive stakeholder workshop with park staff (see Appendix 5.5 for a list of attendees and site visit agenda). Comments or insights captured in this report are not attributed to individual participants but do highlight knowledge shared with the NREL team during the site visit.

The purpose of the NREL site visit was to establish context and nuance for the data and documentation provided by park staff before conducting a more comprehensive operational resilience assessment.

\subsection{Inputs}

Inputs collected and provided by the park are summarized by the hazards, threats, and vulnerabilities data in this section.

\subsubsection{Hazards, Threats, and Vulnerabilities}

The hazards and threats identified through previous studies and by CCNS stakeholders varied depending on the focus areas of the analyses or the skillsets and job responsibilities of the stakeholders. The qualitative and quantitative approach to the park resilience assessment resulted in a large compilation of hazards and threats from reports, documentation, and the stakeholder interviews and brainstorming sessions. The hazards and threats were then grouped into environmental/natural hazards and societal/human threats, as shown below. Resource encroachment and invasive species are examples of stakeholder knowledge informing the relative importance and impact of those events occurring. Some hazards or threats include complexities; economic crashes or large loss in tourism could negatively impact generation of fees but could also reduce stress on resources. These nuances are not captured in the table but were discussed with the team members involved in the workshop and resilience analysis. Examples that were discussed during the on-site workshop at CCNS to identify hazards and threats include the following items:

Environmental/natural:

- Wind, tornados

- Erosion, wave damage, corrosion, shoreline retreat

- Excessive heat

- Snowstorms/nor'easters

- Unpredictable changes in resources (extinctions and infestations)

- Sea level rise, flooding, high tides, and king tides

- Fire

- Shark incidents

- Invasive species 
- Resource encroachments/Cross-boundary resource contamination or extraction

- Water quality degradation.

Societal/human:

- Outside political influences and mandates

- Overuse and congestion

- Cyberattack

- Disease outbreak

- Economic crash/large loss of tourism.

Similarly, a list of vulnerabilities was compiled with CCNS based on existing reports and stakeholder expertise and then grouped by category or theme.

Human/staffing:

- Lack of knowledge of conditions of resources

- Staff turnover, monitoring program gaps in data with staff lapses, inability to identify major changes

- Staffing shortages during an emergency event, lack of staff to respond, emergency personnel response availability with mass safety incident, hiring needs are not aligned with response team

- Loss of expertise and skillsets, institutional knowledge gaps.

Data/information and communications:

- Unmapped utilities, lack of blueprints for infrastructure systems

- Unreliable radio and IT connectivity.

Process/procedures:

- Inflexible approach or ability to rapidly repair damage

- Inaccurate or unreliable "dig safe" information and procedures prior to underground work, which can lead to damaging utility lines and other underground systems.

Infrastructure:

- Aging infrastructure

- Lack of on-site fuel (transportation and heating), especially during sustained winter periods

- Physical security

- Lack of tree maintenance along roadways and utility lines

- Off-road vehicle access challenges

- Low-lying roads susceptible to flooding

- Not enough cooling areas for public during heat events

- Seasonal fluctuation in infrastructure demands

- Site and facility access during weather events (snowstorms and flooding)

- No alternatives to access if compromised. 
Each of the hazards and threats was linked with a vulnerability and vice versa when compiled into a risk matrix, as is discussed in Section 4.3.2.

\subsubsection{Risks}

The risks associated with CCNS's operations are defined as the combined likelihood and consequences of hazards and threats exposing CCNS vulnerabilities. Scores were assigned to each of the hazards, threats, and vulnerabilities based on available data or through stakeholder interviews and expert opinion. Scores help demonstrate the relative importance of each component of risk. Scores were assigned in a risk matrix (see Appendix 5.6) to illustrate priority areas to address with mitigation solutions and highlight trends or root causes of vulnerabilities, as described in Section 3.2. The risk matrix was used for prioritization of risks to address through solution development and was used as an iterative tool to understand the relationships between hazards, threats, and vulnerabilities within CCNS's infrastructure systems and operations. For example, in Figure 5 white cells indicate a lack of relationship between a hazard or threat and a vulnerability (e.g., coastal erosion does not impact IT networks under baseline conditions).

\begin{tabular}{|c|c|c|c|c|c|c|c|c|c|c|c|c|c|c|c|c|c|c|}
\hline & 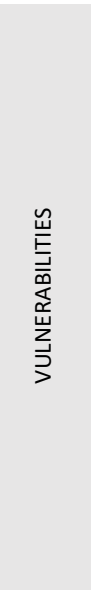 & 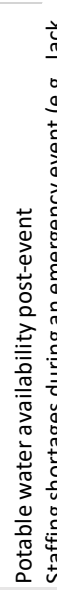 & 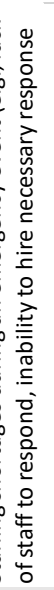 & 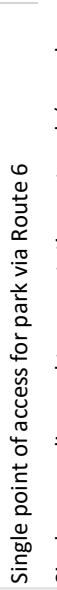 & 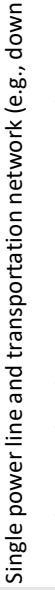 & 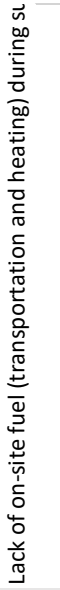 & 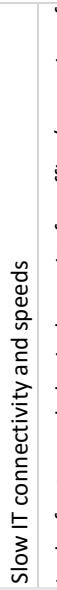 & 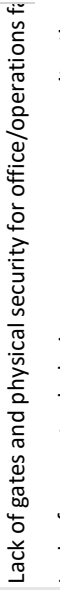 & 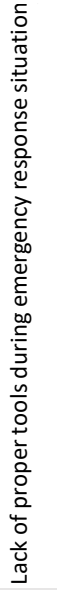 & 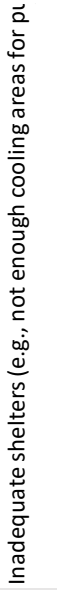 & 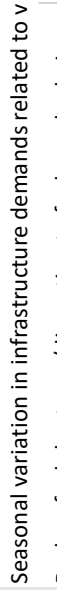 & 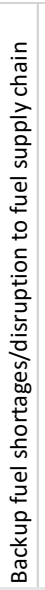 & 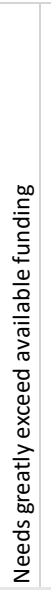 & 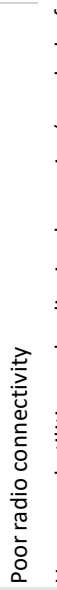 & 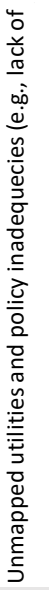 & 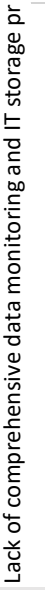 & 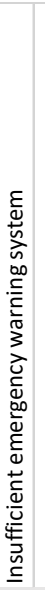 & 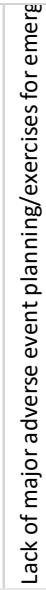 \\
\hline HAZARDS \& THREATS & SCORE & 10 & 10 & 9 & 9 & 9 & 8 & 8 & 8 & 7 & 7 & 7 & 7 & 6 & 6 & 6 & 6 & 6 \\
\hline \multicolumn{19}{|l|}{ Environmental/Natural } \\
\hline High coastal storm surge & 10 & 100 & 100 & 90 & 90 & 90 & & 80 & 80 & 70 & 70 & 70 & 70 & 60 & 60 & 60 & 60 & 60 \\
\hline $\begin{array}{l}\text { Storms: Nor'easters, Tropical Storms, } \\
\text { Hurricanes Cat-1 }\end{array}$ & 10 & .00 & 100 & 90 & 90 & 90 & 80 & 80 & 80 & 70 & 70 & 70 & 70 & 60 & 60 & 60 & 60 & 60 \\
\hline Coastal erosion and shoreline retreat & 9 & & 90 & 81 & 81 & 81 & & 72 & 72 & 63 & 63 & 63 & 63 & 54 & 54 & 54 & 54 & 54 \\
\hline Hurricane Cat 2-3 & 8 & 80 & 80 & 72 & 72 & 72 & 64 & 64 & 64 & 56 & 56 & 56 & 56 & 48 & 48 & 48 & 48 & 48 \\
\hline Increase in daytime temp & 8 & 80 & 80 & 72 & 72 & 72 & 64 & 64 & 64 & 56 & 56 & 56 & 56 & 48 & 48 & 48 & 48 & 48 \\
\hline Sea level rise & 8 & & 80 & 72 & 72 & 72 & & 64 & 64 & 56 & 56 & 56 & 56 & 48 & 48 & 48 & 48 & 48 \\
\hline Flooding & 8 & 80 & 80 & 72 & 72 & 72 & & 64 & 64 & 56 & 56 & 56 & 56 & 48 & 48 & 48 & 48 & 48 \\
\hline Shark incidents & 8 & 80 & 80 & 72 & 72 & 72 & 64 & 64 & & 56 & 56 & 56 & 56 & 48 & & 48 & 48 & 48 \\
\hline $\begin{array}{l}\text { Water quality degradation - salt water } \\
\text { intrusion and septic leakage (fresh water }\end{array}$ & 8 & & & & & & & & & & & & & & & & & \\
\hline degradation) & & 80 & 80 & 72 & 72 & 72 & & 64 & 64 & 56 & 56 & 56 & 56 & 48 & 48 & 48 & 48 & 48 \\
\hline $\begin{array}{l}\text { Water quality degradation - ocean acidification } \\
\text { (marine water quality) }\end{array}$ & 8 & 80 & 80 & 72 & 72 & 72 & & 64 & 64 & 56 & 56 & 56 & 56 & 48 & & 48 & 48 & 48 \\
\hline Highest monthly tides/King tides & 8 & 80 & 80 & 72 & 72 & 72 & 64 & 64 & 64 & 56 & 56 & 56 & 56 & 48 & 48 & 48 & 48 & 48 \\
\hline Coastal water quality & 7 & 70 & 70 & 63 & 63 & 63 & & 56 & 56 & 49 & 49 & 49 & 49 & 42 & & 42 & 42 & 42 \\
\hline High wind damage & 7 & 70 & 70 & 63 & 63 & 63 & 56 & 56 & 56 & 49 & 49 & 49 & 49 & 42 & 42 & 42 & 42 & 42 \\
\hline Increased exposure to vector-borne diseases & 7 & 70 & 70 & 63 & 63 & 63 & & 56 & & 49 & 49 & & 49 & 42 & & 42 & 42 & \\
\hline
\end{tabular}

Figure 5. Snapshot of CCNS's risk matrix 
The areas of greatest concern (a combined score over 70) for CCNS are as follows.

Hazards and threats:

- High coastal storm surge

- Coastal erosion

- Storms

- Increase in daytime temperatures

- Sea level rise, highest monthly tides, and king tides

- Shark incidents

- High wind damage

- Flooding

- Water quality degradation

- Disease outbreak.

Vulnerabilities:

- Lack of water, power, transportation, and communications infrastructure redundancies

- Staffing shortages during emergency events

- Lack of on-site fuel (transportation and heating) during sustained winter periods, impacts pipes

- Slow connectivity and speeds of IT networks

- Physical security

- Lack of proper tools during an emergency response situation

- Lack of adequate shelters

- Seasonal variation in infrastructure demands related to visitation numbers in winter and summer

- Backup fuel shortages/disruption to fuel supply chain

- Needs greatly exceed available funding.

More details are provided in the risk matrix for CCNS staff to use as an iterative tool to update as conditions change and resilience solutions are implemented. The risk matrix is included in Appendix 5.6.

Additionally, maps were created to help CCNS visualize assets that are at highest risk, using exposure rankings. The asset exposure rank was derived from combined coastal hazards and climate change factors (i.e., erosion, flooding, storm surge, sea-level rise, and historical flooding). Figure 6 is an example of the infrastructure and asset exposure mapping that was done for Provincetown, Massachusetts. Exposure ranking is illustrated by asset as high, moderate, low, and minimal, where a high ranking is colored red, moderate is orange, and the lower ranking exposures are yellow. This illustration of the exposure rankings allows CCNS staff to understand the highest-risk assets that need to be prioritized to address through resilience solutions. For example, the Race Point Ranger Station and adjacent trail, museum, boardwalk, bathhouse, generator, facility, and buildings are all highly exposed assets. The cottages along the shoreline are also considered to be buildings with high exposure rankings. The solutions to 
address the high exposure rankings for the Race Point Ranger station are included as higher priority solution sets. Similar maps of each municipality are included in Appendix 5.1.

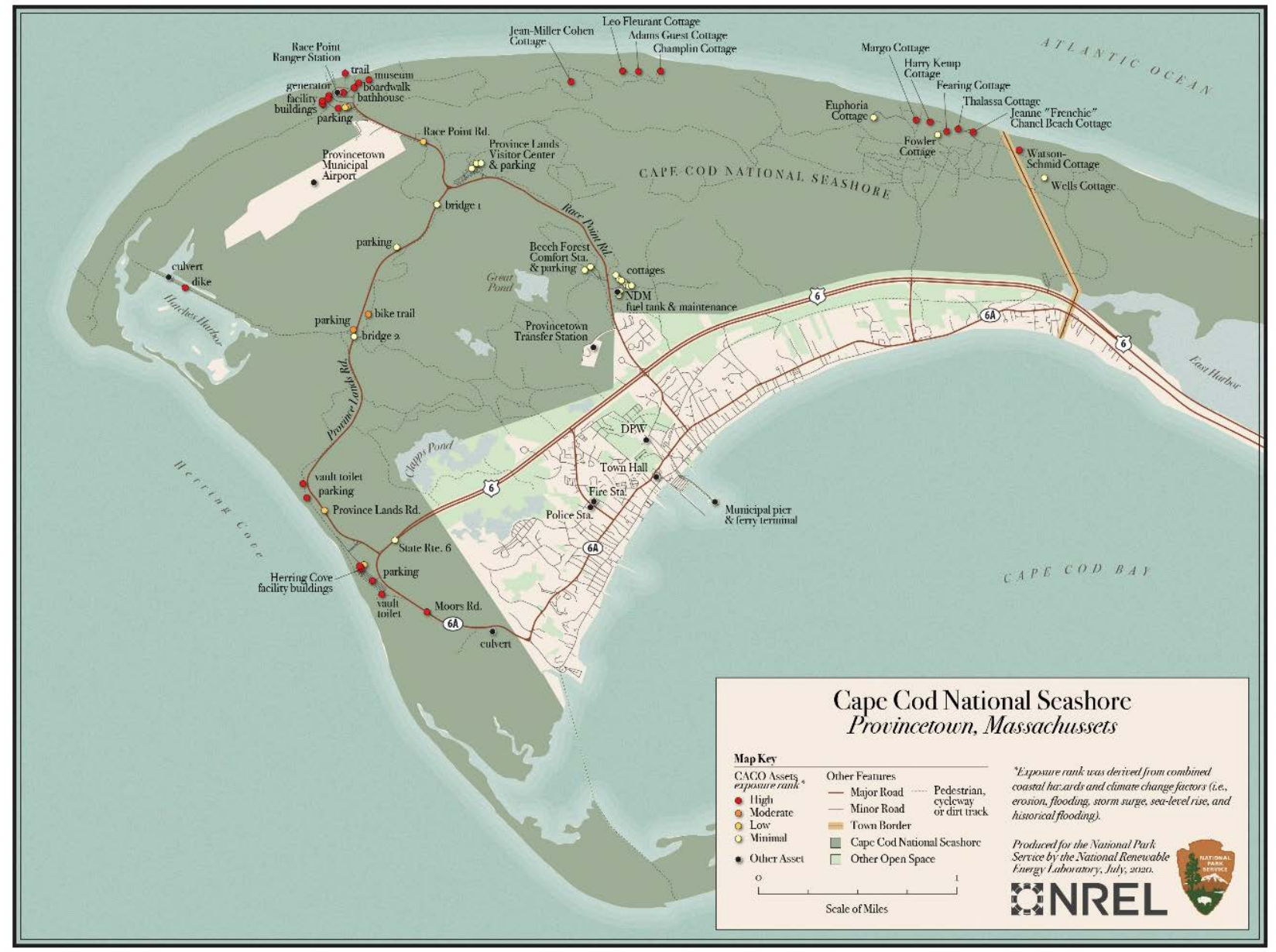

Figure 6. Map of Provincetown, Massachusetts, and infrastructure asset exposure Image by Billy Roberts, NREL

\subsection{Results}

The risk matrix was used to understand the areas of greatest concern at CCNS, then was used to brainstorm potential solutions. Ideally solutions will incorporate a range of implementation complexity (e.g., easy to difficult) and costs (e.g., low-hanging fruit to higher capital costs), and will address risks through mitigation solutions or holistic resilience solutions. Solutions that simultaneously address multiple related vulnerabilities, those that are easy to implement, and those that addressed risks that were likely to occur and would have a significant impact on CCNS's infrastructure or operations are included in this section.

\subsubsection{Solutions}

Opportunities are summarized for the highest-priority risks in terms of technological and operational solutions. Technological solutions are those that require investment in technologies for additional resilience, such as radio towers or redundant systems for backup power at key 
facilities for continued operation. Operational solutions encompass funding, policies, and processes that improve resilience across CCNS's operations. Approximately 30 solutions were brainstormed with park staff and are included in the Solutions Tab in the Excel Risk Matrix in Appendix 5.6. The operational opportunities that were considered the of highest importance are shown in Table 3 by vulnerability being addressed and the facility or asset relevant to the vulnerability.

Additionally, NREL used a techno-economic optimization tool called REopt ${ }^{\mathrm{TM}}{ }^{4}$ to assess solar photovoltaic (PV) and battery storage systems across CCNS. REopt is a modeling platform for distributed energy resource optimization and integration used to identify cost-optimal system sizes and dispatch to minimize the life cycle cost of energy at the sites evaluated. The model considers sites' electricity consumption, electric utility costs, the capital and operation and maintenance costs of solar PV and battery storage, financing costs and incentives, electric utility interconnection and net metering policies, and availability of land, rooftop, and carport areas for solar PV development.

The REopt screening was based on monthly CCNS energy consumption and billing data for 78 electric meters across CCNS, provided to NREL by CCNS staff. Two analyses were completed:

1. Grid-connected economics of solar plus storage (identifying cost-optimal PV and battery sizes to minimize life cycle electricity costs during normal grid-connected operations)

2. Resilience sizing and economics of solar plus storage for the Headquarters (HQ) complex as well as impact of a potential propane generator and fuel tank (identifying cost-optimal PV and battery sizes to minimize life cycle electricity costs while also requiring that the system can survive user-specified simulated electric grid outages).

Lifecycle costs of electricity include grid purchases, capital costs, operations and maintenance costs, and any fuel consumed over a 25-year analysis period. Findings from the REopt study can be found in Section 5.2.

\footnotetext{
${ }^{4}$ For more information, see https://reopt.nrel.gov/.
} 
Table 3. Highest-Priority Operational Solutions

\begin{tabular}{|c|c|c|}
\hline Vulnerability to Address & Solution Description & Facility or Asset \\
\hline Potable water availability post-event & $\begin{array}{l}\text { (A) Ensure Provincetown waterlines, Highlands } \\
\text { Center water tank, Marconi Site water tower and } \\
\text { B-well, Eastham waterlines are operational in } \\
\text { power outage; determine water system and } \\
\text { storage tank availability in power outage via } \\
\text { gravity and/or generator backup; and (B) Deploy } \\
\text { small-scale portable, potable water tanks (e.g., } \\
\text { water buffalo stationing to serve residents and } \\
\text { visitors whose wells are unavailable post-event) }\end{array}$ & Water \\
\hline $\begin{array}{l}\text { Staffing shortages during an emergency } \\
\text { event (e.g., lack of staff to respond, } \\
\text { inability to hire necessary response team, } \\
\text { emergency personnel availability for } \\
\text { specific incidents) }\end{array}$ & $\begin{array}{l}\text { A) Memoranda of understanding for responders } \\
\text { from neighboring communities; emergency } \\
\text { teams trained and at the ready; training for } \\
\text { fulltime, regular staff; and (B) Activate Incident } \\
\text { Command System as needed in coordination } \\
\text { with the Massachusetts Emergency Management } \\
\text { Agency and Barnstable County emergency } \\
\text { planning departments; develop working } \\
\text { relationship on major hazard response with } \\
\text { county and towns for more robust response } \\
\text { capability; personnel development }\end{array}$ & Personnel \\
\hline $\begin{array}{l}\text { Lack of medical facilities, major adverse } \\
\text { event planning/exercises for event } \\
\text { planning, lack of proper tools during } \\
\text { emergencies, single point of access, and } \\
\text { staffing shortages during emergencies. }\end{array}$ & $\begin{array}{l}\text { Broader regional coordination is needed, as well } \\
\text { as individual preparedness. Individual } \\
\text { preparedness includes following FEMA guidelines } \\
\text { (e.g., one gallon of water per day per person, } \\
\text { food [3-day supply], batteries for flashlights and } \\
\text { radios, generators/fuel, first aid kits, whistle [to } \\
\text { call for help], duct tape, moist towelettes, } \\
\text { wrench/pilers [to turn off utilities], can opener, } \\
\text { local maps, etc.) } \\
\text { Additionally, a new medical facility is being built } \\
\text { near the Orleans rotary by Cape Cod Healthcare, } \\
\text { which will require coordination with NPS to } \\
\text { understand triage and emergency } \\
\text { procedures/protocols. }\end{array}$ & Personnel \\
\hline Single point of access for park via Route 6 & $\begin{array}{c}\text { Examine water and air options for emergency } \\
\text { situations; raise Route } 6 \text { at Blackfish Creek and } \\
\text { Orleans Rotary; deployment of rescue boats; } \\
\text { med-evac helispots }\end{array}$ & Transportation \\
\hline $\begin{array}{l}\text { Downed wires and trees impede site access } \\
\text { post-event }\end{array}$ & $\begin{array}{c}\text { (A) Redundant systems to power critical facilities; } \\
\text { chainsaw crews and equipment fueling backup, } \\
\text { (e.g., generators and fuel can availability); and (B) } \\
\text { In-house project to install generators at fuel } \\
\text { tanks at Little Creek staging area and North } \\
\text { District Maintenance for chainsaw and heavy } \\
\text { equipment use }\end{array}$ & $\begin{array}{l}\text { Personnel, } \\
\text { Equipment }\end{array}$ \\
\hline $\begin{array}{l}\text { Lack of on-site fuel (transportation and } \\
\text { heating) during sustained winter periods, } \\
\text { impacts pipes }\end{array}$ & $\begin{array}{l}\text { (A) Redundant systems to heat critical facilities } \\
\text { and operations and fuel vehicles and equipment; } \\
\text { and B) Generators and/or solar battery storage }\end{array}$ & Equipment \\
\hline Slow IT connectivity and speeds & $\begin{array}{c}\text { Boost system with repeaters, and invest in IT } \\
\text { upgrades }\end{array}$ & Telecommunications \\
\hline
\end{tabular}




\begin{tabular}{|c|c|c|}
\hline Vulnerability to Address & Solution Description & Facility or Asset \\
\hline $\begin{array}{l}\text { Lack of gates and physical security for } \\
\text { office/operations facilities }\end{array}$ & $\begin{array}{l}\text { Enhance physical security and add fire gates } \\
\text { where needed }\end{array}$ & $\begin{array}{l}\text { Security } \\
\text { infrastructure; } \\
\text { buildings }\end{array}$ \\
\hline $\begin{array}{l}\text { Lack of proper tools during emergency } \\
\text { response situations (e.g., generators, } \\
\text { chainsaws, earth moving equipment, etc.) }\end{array}$ & $\begin{array}{c}\text { Examine emergency equipment inventory, } \\
\text { maintain inventory, and purchase additional } \\
\text { equipment; memoranda of understanding for } \\
\text { personnel and equipment in response situations. } \\
\text { This effort should include town, county, and } \\
\text { Massachusetts Emergency Management Agency } \\
\text { equipment }\end{array}$ & Equipment \\
\hline $\begin{array}{l}\text { Inadequate shelters (e.g., not enough } \\
\text { cooling areas for public during extreme } \\
\text { heat) and air conditioning in offices }\end{array}$ & $\begin{array}{c}\text { Assess need for added shelters at beaches } \\
\text { and high visitor use areas; and, improve } \\
\text { natural/passive ventilation or add } \\
\text { mechanical cooling systems }\end{array}$ & $\begin{array}{l}\text { Buildings; heating, } \\
\text { ventilation, and } \\
\text { air conditioning } \\
\text { systems }\end{array}$ \\
\hline $\begin{array}{c}\text { Seasonal variation in infrastructure } \\
\text { demands related to visitation numbers } \\
\text { in winter and summer }\end{array}$ & $\begin{array}{c}\text { Regional response planning to address both } \\
\text { winter conditions to serve vulnerable } \\
\text { populations and large-scale visitation in } \\
\text { summer }\end{array}$ & All \\
\hline $\begin{array}{c}\text { Backup fuel shortages/disruption to } \\
\text { fuel supply chain }\end{array}$ & $\begin{array}{c}\text { Redundant fuel systems; memoranda of } \\
\text { understanding for resupply; alternative } \\
\text { means of transport and heating }\end{array}$ & $\begin{array}{l}\text { Transportation; } \\
\text { renewable energy }\end{array}$ \\
\hline Poor radio connectivity & Upgrade radio system & Communications \\
\hline
\end{tabular}

Exit interviews and consolidation of oral histories from long-tenured staff will be conducted and documented to allow for smooth transitions when staff retire or leave CCNS employment to capture institutional knowledge. Solutions are also categorized by funding needs, prioritization of the solution in terms of timeframe, and whether the solution is a policy, procedure, training, technology, or includes a capital project. Ideally, a portfolio of solutions would include a mixture of solution types and have near- and long-term timeframes for implementation. Similarly, lowcost solutions could be identified in tandem with larger, more costly projects, such as capital projects.

\subsubsection{Capital Building and Utility Infrastructure Solutions}

Other solutions brainstormed concerning buildings and utilities included the following:

- Essential park facilities should be replaced in a location-specific way or relocated. The national seashore has identified a preference for allowing natural shoreline processes to take place unimpeded, while also counteracting human-caused disturbances. As facilities are threatened by coastal erosion (such as the beach bathhouses and parking lots) and storm surge - both exacerbated by sea level rise - consider whether elevation and/or retreat, dune restoration, sand fencing, and other mitigations will be undertaken; extensive analysis of natural, coastal processes is undertaken when selecting the appropriate facility replacement strategy.

- Work with utility companies to map electric and telecommunications lines; improve utility-provided dig-safe program; establish up-to-date centralized master plans/maps and 
drawings of utilities. This solution addresses unsafe procedures related to digging and construction within the park's boundaries.

- Establish decentralized backup IT storage for park databases; database manager to improve slow connectivity.

- Implement plan to replace problem areas first to address public and environmental health in relation to aging septic systems and failing wastewater pumps. Gravity-fed systems could be included where major renovations are occurring to allow water to be distributed during a power outage.

- Analog backup systems; radio system use; emergency temporary cell antenna deployments to improve area-wide cell phone coverage for a days-long potential outage.

- Elevate or identify alternate transportation routes; improve culverts and bridges to address flooding related to low-lying roads within the park (e.g., Herring River Restoration Project and Moors Road).

- Create vegetation management plan for key areas and train staff/add to schedule for routine maintenance to address vegetation management challenges along infrastructure routes and corridors and around structures.

\subsubsection{Emergency Preparedness and Response:}

A number of solutions were grouped together, as they relate to emergency preparedness and response:

- Establish more robust alerts for emergency management and emergency warning systems.

- Participate in annual exercises with local and regional emergency response entities and actively maintain hazard mitigation plans and implementation. Continue to participate in: tabletop exercises with U.S. Coast Guard in relation to the Cape and Islands oil spill response contingency plan; seek additional interagency involvement in oil and hazardous materials emergency action planning.

- Create a memorandum of understanding for a transportation plan for care facilities/emergency situations.

- Identify triage centers, regional shelters, and shelter-in-place locations for better emergency planning, including coordination with the new Cape Cod Healthcare facility being built near the Orleans rotary. This should be done in coordination with MEMA and Barnstable County, who are the coordinators of these facilities.

- Conduct periodic emergency route planning exercises within the Outer Cape towns and across the entire Cape.

- Establish an emergency response capability and coordination plan to assist vulnerable residents and park visitors in harm's way. Continue to participate in meetings and briefings of regional emergency management and storm preparedness teams with other agencies, the county, and the towns; reinforce mutual aid assistance advance planning coordination activities; and project what adjustments are needed to emergency Incident 
Command System plans to include regional emergency management and storm preparedness teams for major adverse events to develop an adaptive framework for future emergency and storm events. Participate with county and towns on vulnerability and preparedness outreach to communities and visitors on known response plans and better advertise available alert systems and preparedness kits at each home and business. Exit interviews and consolidation of oral histories from long-tenured staff will be conducted and documented to allow for smooth transitions when staff retire or leave CCNS employment to capture institutional knowledge.

\subsubsection{Coastal Resilience Projects}

CCNS staff created a list of 25 coastal resilience priority projects to integrate into the NPS's Project Management Information System (PMIS) tool (see Section 4.1). Table 4 is a working list of projects prioritized by key areas and risk reduction potential, including potential cost estimates to help gauge level of magnitude for implementation. 
Table 4. Highest-Priority Facility Solutions by Cost and PMIS Project Funding Request Number

\begin{tabular}{|c|c|}
\hline PMIS \# & PMIS Title \\
\hline 227735 & Reconstruct Mill Creek Water Control Structure to Support Large-Scale Herring River Restoration \\
\hline 302231 & Replace Fee Booths at Five CCNS Ocean Beach Entrance Fee Locations \\
\hline 306183 & Rehabilitate and Stabilize Hatches Harbor Dike \\
\hline 313692 & Purchase Handicapped Accessibility Equipment for CCNS Beaches \\
\hline 314845 & Repair Coast Guard Cranberry Bog Bridge for Access to Beach Facilities at CCNS \\
\hline 313615 & Replace Buttonbush Trail Boardwalk for Visitor Safety \\
\hline 307224 & Replace Lifeguard Chairs with New Chairs Designed for Better Water Surveillance \\
\hline 317519 & Rehab Province Lands Bike Path \\
\hline 317495 & Rehab Nauset Bike Path \\
\hline 317442 & Relocate Herring Cove Beach Facilities Inland \\
\hline 317533 & Relocate South Parking Lot Herring Cove Beach \\
\hline 258723 & Relocate Marconi Beach Facilities to Adapt to Coastal Erosion and Maintain Recreation Opportunities \\
\hline 257213 & Remove Hazardous Vegetation from Structures (Residences, Facilities, Other Buildings) \\
\hline 303814 & Replace CCNS Shower Towers and Bottle Fillers at Ocean Beach Visitor Facilities and Headquarters \\
\hline 291511 & Replace Mobile Column Lift for Maintenance of Shuttle Trams and Trailing Cars \\
\hline 180134 & Replace 1990 John Deere 2335 Tractor and Flail Mower \#156029 With Equivalent \\
\hline 275131 & Rehabilitate the Beech Forest Boardwalk to Improve Safety and Accessibility \\
\hline 154114 & Replace Beach Shuttle to Serve Coast Guard Beach \\
\hline 206381 & Rehabilitate Buttonbush Braille Trail to Eliminate Hazards \\
\hline 154020 & Expand Beach Shuttle to Nauset Light Beach \\
\hline 314946 & Remove Debris on Beach and in Surf Zone from Six CCNS Beaches \\
\hline 162674 & Purchase Handicapped Accessibility Equipment for CCNS Beaches \\
\hline 311566 & Nauset Light, Driveway Relocation \\
\hline 310539 & Rehabilitate White Cedar Swamp Trail to Improve Safety \\
\hline 310422 & Repair and Resurface 10 Most Heavily Used CCNS Trails (FY 2022-25) \\
\hline
\end{tabular}




\section{Next Steps}

Risk can be mitigated through holistic solutions, which address vulnerabilities within CCNS's infrastructure and operations. This section outlines potential steps for implementation, based on discussions with park staff.

\subsection{Future Park-Level Project Planning}

CCNS staff have begun planning for implementation by submitting proposals for project funding to various funding pathways. Information related to the park's Great American Outdoors Act Facility Investment Plan-related data can be found in the relevant Facility Planning BranchStrategic Facility Investment Planning SharePoint Site. This process allows park staff to create projects with an estimated project cost. CCNS submitted a project proposal to bundle PMIS projects that have a common theme of adaptive measures to address park facilities and infrastructure that are either impacted, threatened, or necessary to protect against coastal erosion, sea level rise, ocean and land temperature increases, and major storm occurrences (see Table 4); the project has not been selected for funding. The environmental factors combine to challenge the park to provide safe and reliable facilities that will continue to support park operations and recreation while being responsive to resource protection concerns. There are no comparable public facilities in the six Outer Cape towns. The provided facilities and services are a vital part of seashore operations and are essential for maintaining a safe and enjoyable visitor experience. Other alternatives to sustaining park facilities are not a serious consideration.

The bundle of projects is intended to address coastal vulnerability, including retreat and relocation of two beach facilities, a large beach parking lot, a beach facility septic system, and fee booths for four beaches. Some parking lots currently threatened by erosion cannot be relocated, and in these cases beach accesses and accessibility improvements via beach shuttle expansion are included.

Projects in this bundle are not solely focused on retreat and relocation. Building coastal resilience must also incorporate rehabilitating flood protection resources. A water control structure at Hatches Harbor offers flooding protection for Provincetown Municipal Airport; the airport pre-existed the park's establishment; improvements to its structural stability and tidal flow are needed due to deterioration caused by sea level rise. The Mill Creek water control structure will enable the multi-agency 1,100-acre Herring River estuarine restoration project by regulating tidal flow in the river basin. As the largest coastal wetland restoration within the Gulf of Maine, the project is nationally compelling; it corrects impaired water quality and improves fish habitat and tidal marsh within the 1,100-acre estuary. All restoration is dependent on NPS construction of the Mill Creek water control structure.

With sea level and ground water closely linked on Cape Cod, increases in sea level will also influence ground water levels. Low-lying resources located further inland will also be impacted by rising sea levels and flooding. Bicycle and walking trails, which are located adjacent to salt marsh and wetlands, are directly affected and will require attention and rehabilitation; inundation of the low-lying portions of trails is increasingly common.

Episodic storm events are becoming more frequent and powerful, resulting in a more frequent need to repair or replace storm-damaged structures. With coastal facilities built in the 1960s and 
1970s within and outside the park increasingly threatened, it could be efficient to fund the park's proposals as a new generation of national seashore beach and recreation facilities.

Several replacement projects will support ongoing beach maintenance and operation activities, including shark surveillance by lifeguards, access trail work, and beach wheelchair access. These projects will address long-term critical health and safety issues, as well as accessibility compliance measures, sustainability, and energy conservation, and eliminate many deferred maintenance issues, all of which are important for suitable NPS facilities. The current replacement value of facilities is approximately $\$ 91$ million.

The saltwater environment is hard on facilities in many ways, and the challenges of managing and maintaining facilities in the coastal environment are compounded by the powerful coastal forces that are becoming more extreme with climate change. The deficiencies in the high-priority assets that we have identified will be corrected and returned to acceptable or very good condition.

In a few locations, facility and utility removal and relocation must occur before the area is undermined to the point where removal is no longer feasible or safe, risking septage and facilities falling onto the beach and into the Atlantic. The relocations will avoid catastrophic failure and ensure continuation of park operations and visitor services.

Once CCNS facilities are in acceptable condition and location, a defined preventative maintenance strategy will be developed for operations and maintenance. The affected assets will be annually maintained through regular cyclic maintenance. Along with making them more resilient, scheduled preventative maintenance will be effective at deterring a maintenance backlog in the future.

The facilities are inherently federal facilities and are not projected to be operated by partners or towns; however, in the case of the Mill Creek project, a small NPS investment yields significant leveraging by other entities. The NPS is collaborating with multiple federal agencies from three different departments as well as state agencies, two local municipalities, and nonprofit groups. Members of this collaborative team contribute to the funding, planning, design, review, and implementation of this restoration effort. Utility connections to municipal services are not viable, as town-wide utility services are not available nearby.

The Mill Creek water control structure is one of eight infrastructure improvements necessary for the Herring River Restoration project and is the only structure that will be located on NPS lands. The \$6 million NPS investment effectively leverages over $\$ 60$ million in total restoration efforts with the restoration of 800 acres of estuary (all within the boundary of the park) that benefits ecosystem function, shellfish interests, recreational opportunities, and corrects an impaired water quality site. CCNS is dedicated to improving its resilience posture and exploring the various programmatic planning and funding options available is one way in which projects will become implemented and enhancements will be made.

\subsection{Funding Opportunities/Pathways}

Identifying appropriate funding pathways and opportunities for implementation will ensure successful execution of resilience projects. CCNS staff compiled PMIS projects in response to an 
NPS-wide combined call to lay out funding pathways, which is undertaken by the NPS on an annual basis. Table 5 is an example of the various funding opportunities that were considered by CCNS staff to determine relevant project proposals for resilience. The typical funding source requests by CCNS are highlighted in red.

As new funding becomes available, pragmatic approaches will help CCNS staff understand appropriate funding pathways for implementing projects. As an example, on August 4, 2020, the Great American Outdoors Act was signed into law to "significantly help address the historically underfunded, multi-billion-dollar deferred maintenance backlog at our national parks and public lands" (NPS 2021). Revenue from energy development will provide up to $\$ 1.9$ billion a year for 5 years in the National Parks and Public Land Legacy Restoration Fund to provide needed maintenance for critical facilities and infrastructure in our national parks, forests, wildlife refuges, recreation areas, and American Indian schools. The Act will also enable dedicating royalties from offshore oil and natural gas to permanently fund conservation and recreation opportunities through the Land and Water Conservation Fund, estimated to be around $\$ 900$ million a year. 
Table 5. Potential Funding Pathways

\begin{tabular}{|l|l|l|}
\hline \multicolumn{1}{|c|}{ SCC Fund Source Name } & Managed & Fund Years ${ }^{(\mathbf{1})}$ \\
\hline Concessions Franchise Fee (80\%) & & \\
\hline Concessions Franchise Fee (20\%) & Region & No Year \\
\hline Cultural Resources (CRPP) [ONPS] & Region & No Year \\
\hline Cyclic Maintenance & Region & 1 Year \\
\hline Dam and Levee Safety & Region & 2 Years \\
\hline Environmental Management Program & WASO & No Year \\
\hline Environmental Quality Division & WASO & 1 Year \\
\hline Equipment Replacement (Vehicles) & WASO & No Year \\
\hline Equipment Replacement (IT) & Region & No Year \\
\hline Federal Highway Administration Transportation & WASO & No Year \\
\hline Housing Initiative & WASO & No Year \\
\hline Interpretation and Education & WASO & 1 Year \\
\hline Line-Item Construction & WASO & No Year \\
\hline Natural Resource (NRPP) [ONPS] & WASO & 1 Year \\
\hline Recreation Fee (20\% Nationwide) & Region & No Year (3) \\
\hline Recreation Fee Park Rev (80\%) & Region & No Year (3) \\
\hline Recreation Fee (20\% Regional) & WASO & No Year (3) \\
\hline Recreation Fee (PLC 20\%) & WASO & No Year (3) \\
\hline Repair / Rehabilitation & Region & 2 Years \\
\hline Unit Management Plans & WASO & No Year \\
\hline Wildland Fire & WASO & No Year \\
\hline Youth Partnership Programs (YPP) & Year \\
\hline
\end{tabular}

As CCNS works toward implementing resilience solutions, maintaining an updated list of potential funding sources will be important when determining which projects have been funded and implemented and which projects within the solution list could potentially be proposed for future funding as it becomes available.

Aligning planning activities with funding opportunities and program goals will be key to enhancing resilience across the park. 


\section{Appendix}

\subsection{Park Maps}

At the request of CCNS staff, NREL staff created exposure maps of park infrastructure. These maps - by municipality — are included here for reference.

There were no vulnerability maps created for park areas within the towns of Orleans and Chatham. While the NPS has significant landholdings and natural resources on the outer beach of Orleans and Chatham, there are no park administrative facilities or infrastructure within the national seashore boundary. The only built NPS facility within these towns on the barrier beach is the concession-operated Nauset Beach Inn just west of the town-owned Nauset Beach parking and beach administration facilities in Orleans; the town is involved in phased planning to retreat and relocate beach facilities there. 


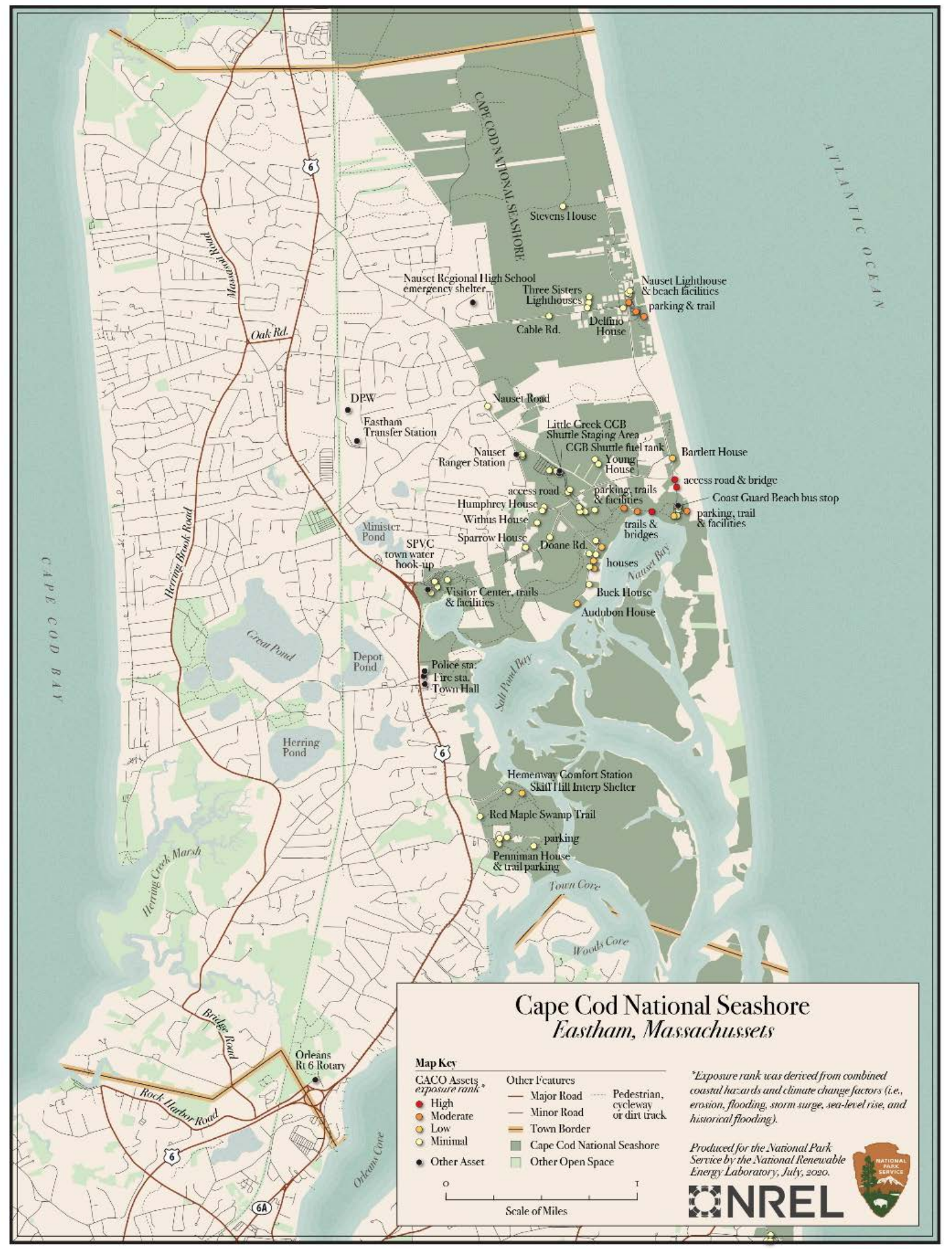

Figure 7. Map of Eastham, Massachusetts, and infrastructure asset exposure Image by Billy Roberts, NREL 


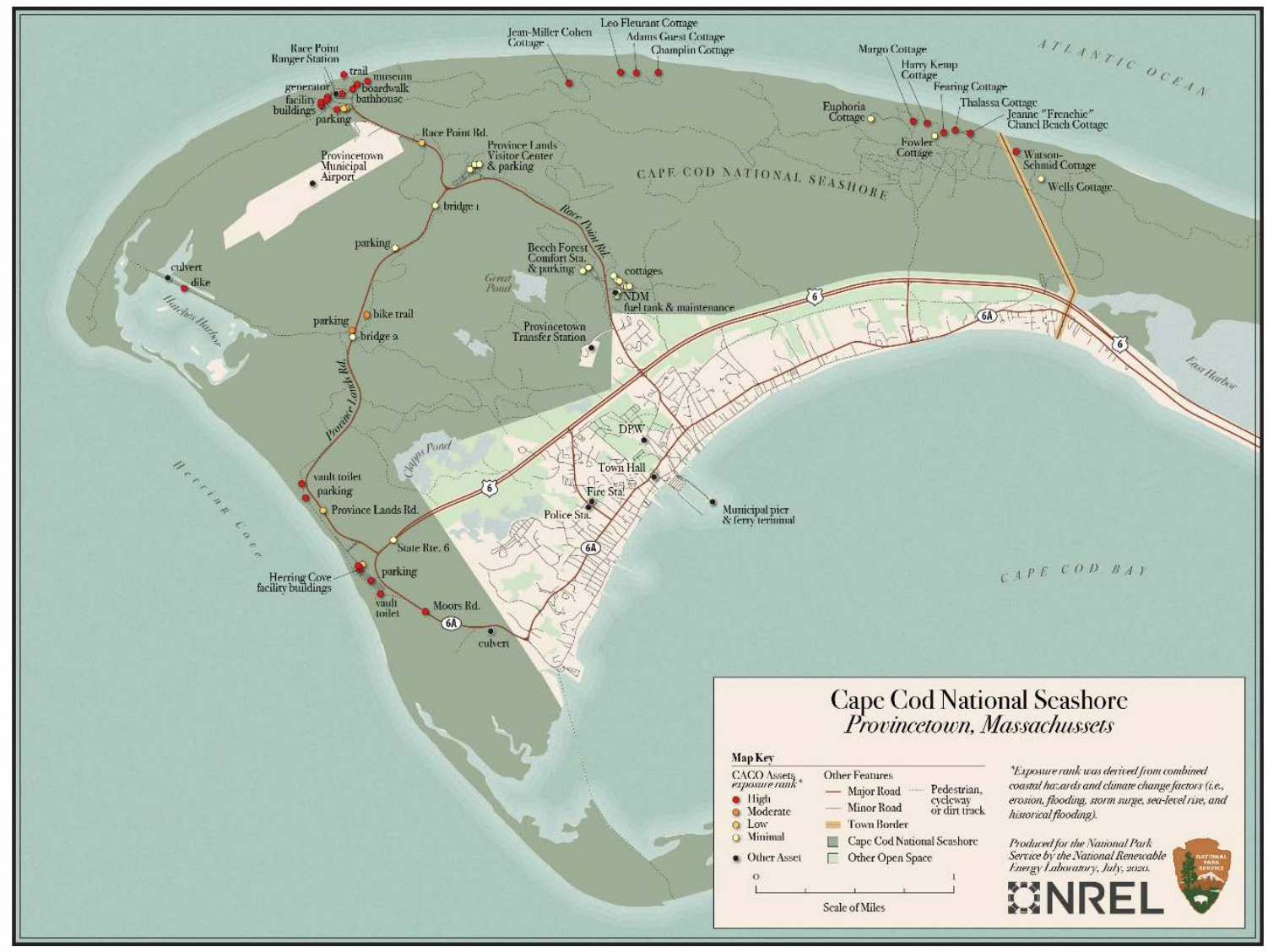

Figure 8. Map of Provincetown, Massachusetts, and infrastructure asset exposure Image by Billy Roberts, NREL 


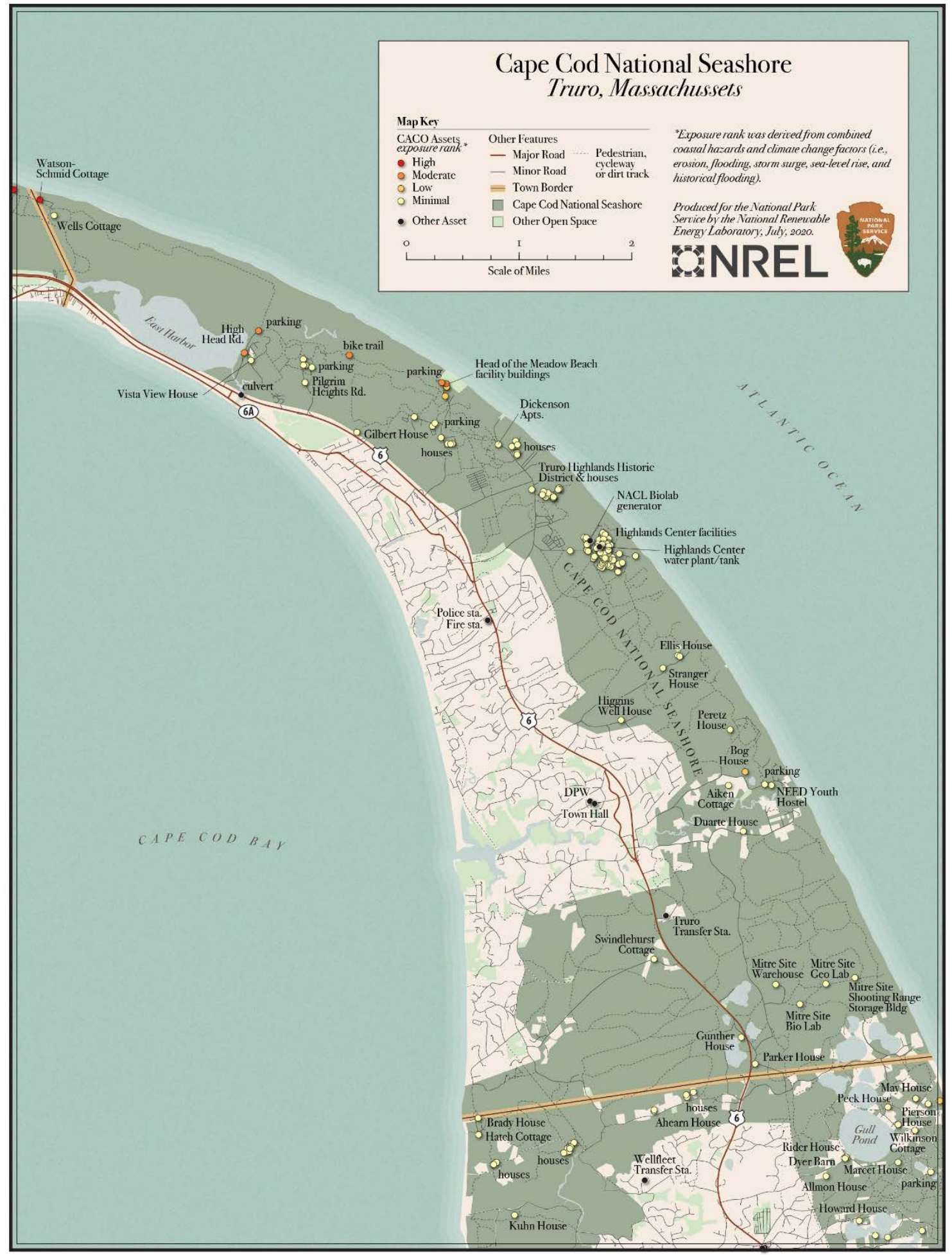

Figure 9. Map of Truro, Massachusetts, and infrastructure asset exposure Image by Billy Roberts, NREL 


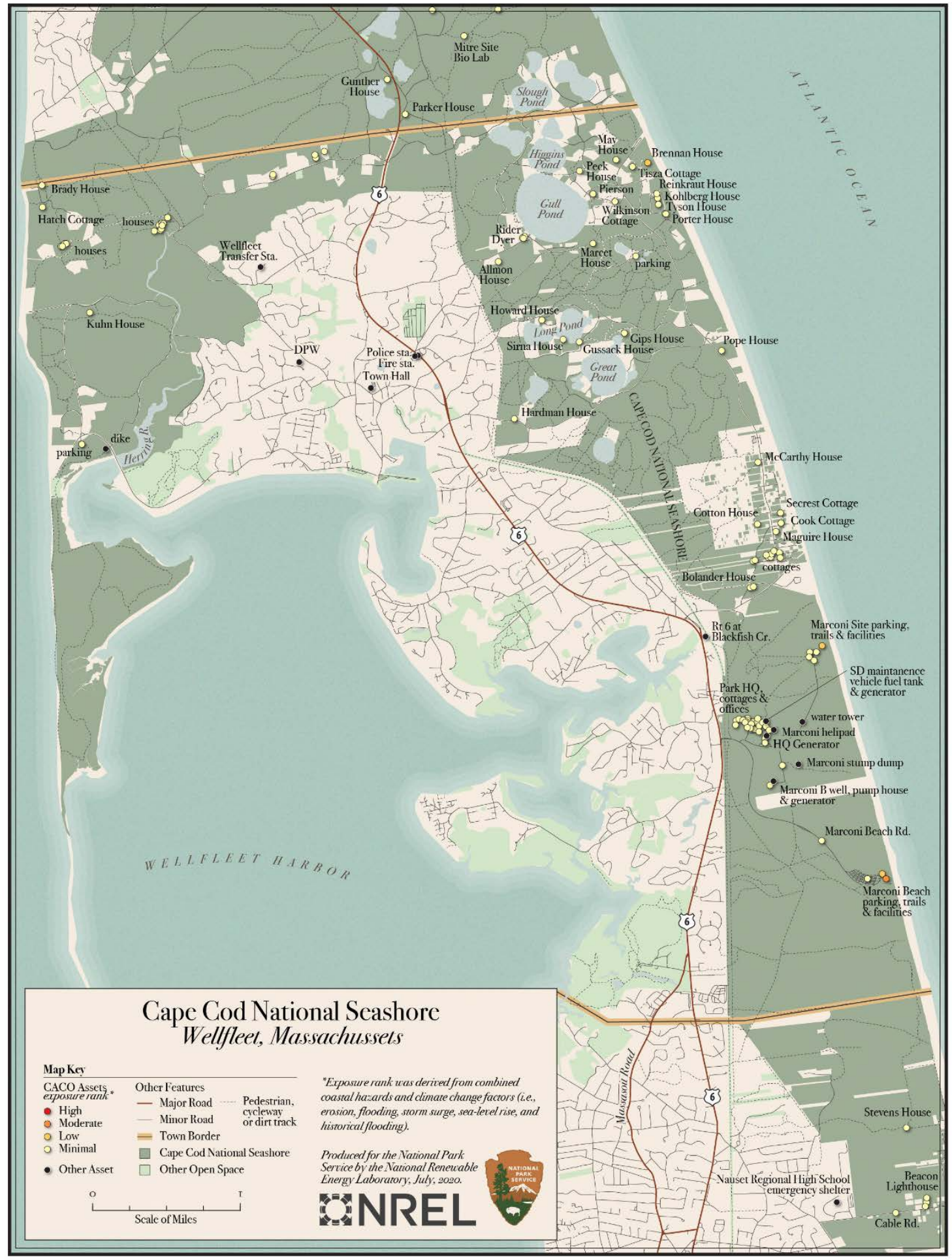

Figure 10. Map of Wellfleet, Massachusetts, and infrastructure asset exposure Image by Billy Roberts, NREL 


\subsection{REopt Analysis and Results}

\subsubsection{Methodology}

NREL used a techno-economic optimization tool called REopt ${ }^{5}$ to assess solar photovoltaic (PV) and battery storage systems across CCNS. REopt is a modeling platform for distributed energy resource optimization and integration used to identify cost-optimal system sizes and dispatch to minimize the life cycle cost of energy at the sites evaluated. The model considers sites' electricity consumption, electric utility costs, the capital and operation and maintenance costs of solar PV and battery storage, financing costs and incentives, electric utility interconnection and net metering policies, and availability of land, rooftop, and carport areas for solar PV development.

This initial screening was based on monthly CCNS consumption and billing data for 78 meters across CCNS, provided to NREL by CCNS staff. Two analyses were completed:

3. Grid-connected economics of solar plus storage

4. Resilience sizing and economics of solar plus storage for the Headquarters (HQ) complex as well as impact of a potential propane generator and fuel tank.

\subsubsection{Inputs and Assumptions}

\subsubsection{Electric Consumption}

To model the electric consumption at these sites, monthly load data from the 78 meters, which are clustered across eight different campuses, was aggregated to understand overall electricity consumption. This data, provided by NPS for 2016 and most of 2019, is shown in Figure 11. Electrical load data from 2016 was used for the analysis as it was available for a complete year. For initial screening purposes, the load was aggregated because Massachusetts allows virtual net metering (see Section 6.2.2.3 for reference), which would allow sites to apply net metering credits across multiple sites.

\footnotetext{
${ }^{5}$ For more information, see https://reopt.nrel.gov/.
} 


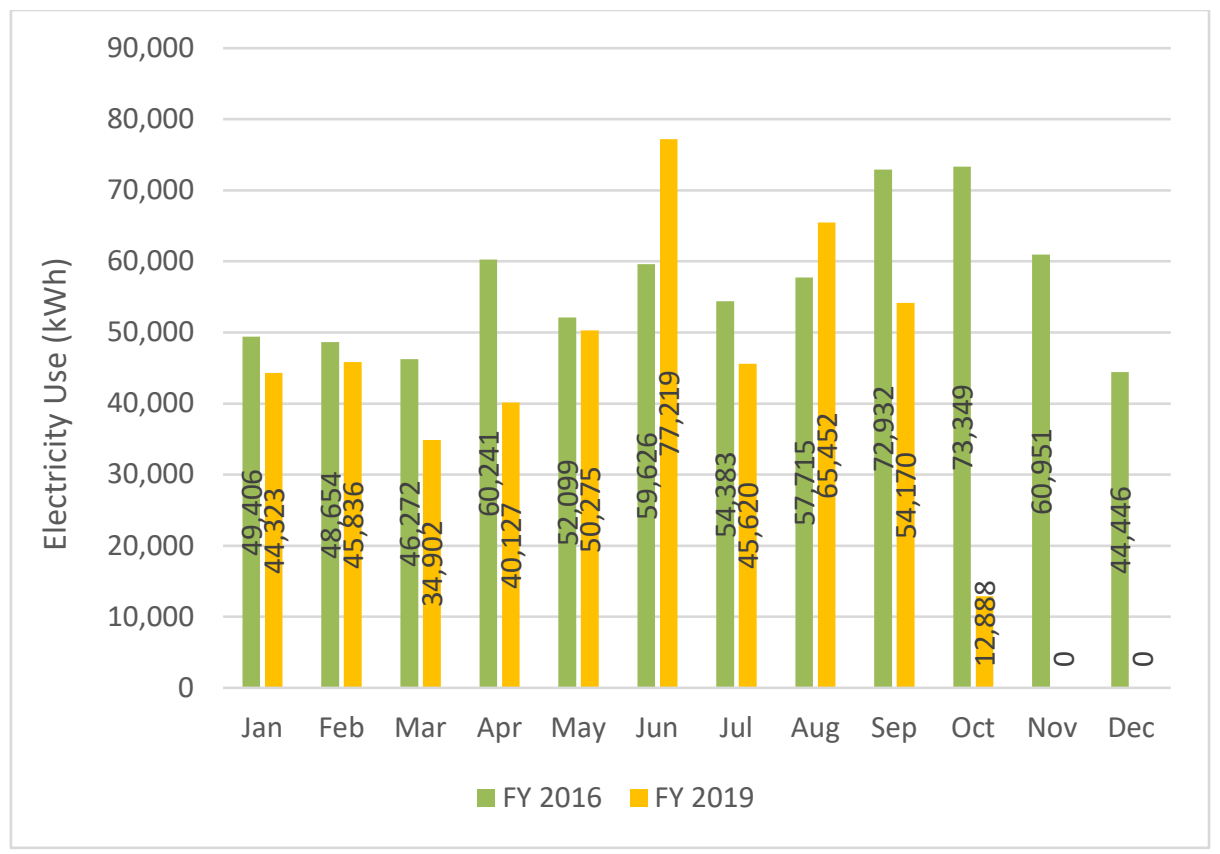

Figure 11. Monthly electric consumption across all 78 buildings, provided by NPS

To develop a simulated hourly electric load profile, DOE Commercial Reference Buildings ${ }^{6}$ were scaled to match CCNS monthly load magnitudes to capture seasonal load patterns throughout the year. The consumption patterns within each month were estimated to be represented by a combination of small offices $(60 \%)$ and small hotels $(40 \%)$, based on facility type and main usage descriptors provided by CCNS along with consumption data. This simulated annual load data can be seen in Figure 12.

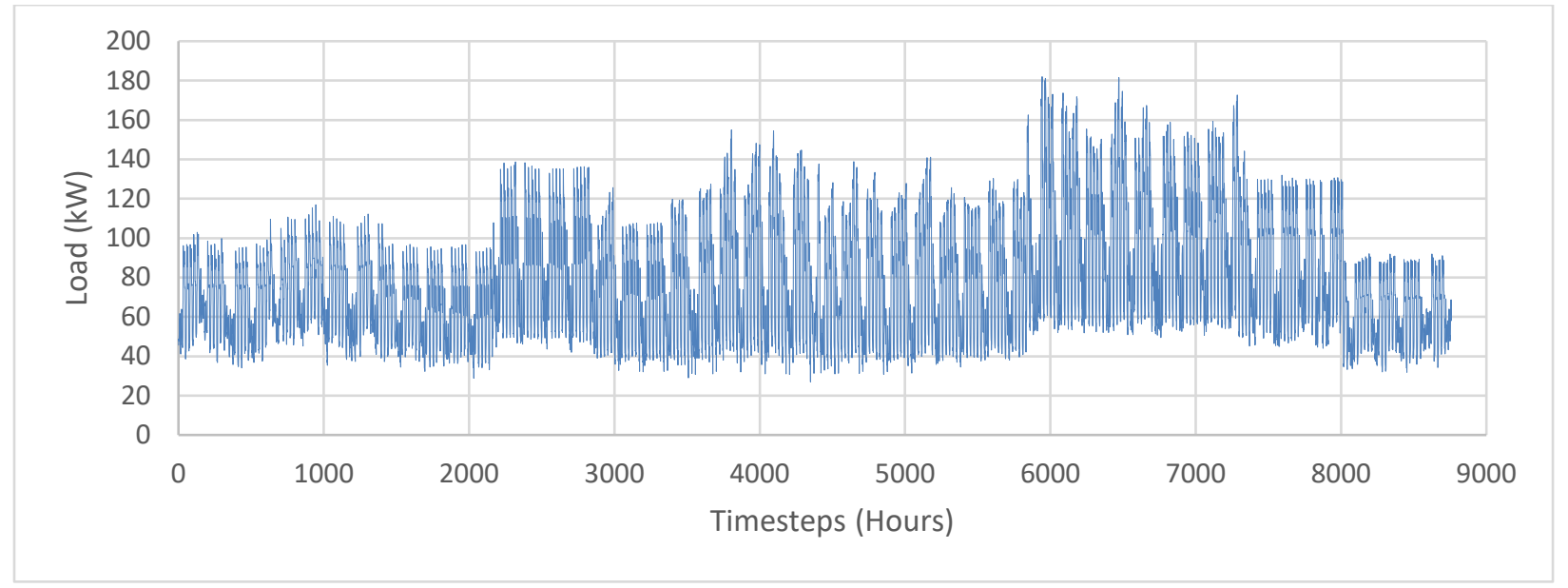

Figure 12. Simulated site load

For the second part of the analysis where PV and battery were evaluated for not only gridconnected value but also resilience value, these assets are assumed to be located at CCNS HQ and thus could only provide electricity for that site during the simulated grid outages. These

\footnotetext{
${ }^{6}$ For more information, see https://www.energy.gov/eere/buildings/commercial-reference-buildings.
} 
week-long outages were simulated from February 8-14 and September 1-7 based on input from CCNS about common outage timing and coincidence of outages with seasonal solar resource. Specifically, the February outage was selected to represent a nor'easter-type winter storm and the September outage was selected to occur during the annual peak load. This simulated critical load during the outages is shown in Figure 13.

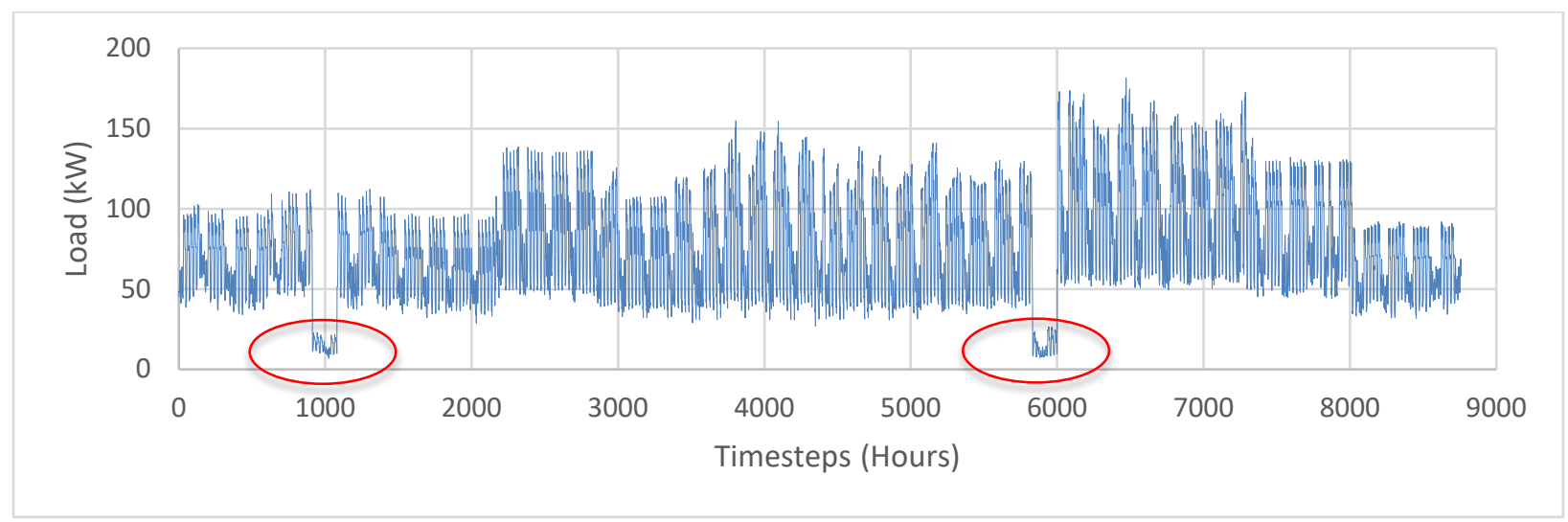

Figure 13. Simulated site load, showing CCNS HQ load as critical load during grid outages (red circles)

\subsubsection{Electric Utility Rates}

The sites receive electricity supply from NextEra Energy Services ${ }^{7}$ and delivery service from Eversource Energy. ${ }^{8}$ These are aggregated under Cape Light Compact, ${ }^{9}$ a community aggregator for the Cape Cod/Martha's Vineyard region.

Based on the electricity bills provided, the meters are on four different Eversource delivery rates: Rate 32 - R-1 Residential (32 meters), Rate 33 - G-1 General Annual (21 meters), Rate 35 - G-1 General Seasonal (15 meters), and Rate 66 - R-1 Residential (10 meters). Because the analysis aggregates all loads and models them as if charged on a single rate at a single meter, Rate 33 was used to model delivery charges, as it best represents the majority of the consumption across the meters on an energy (kWh) basis. The energy and demand charges are summarized in Table 6; overall energy charges total $\$ 0.19498 / \mathrm{kWh}$ and demand charges are $\$ 5.22 / \mathrm{kW}$ over $10 \mathrm{~kW}$.

\footnotetext{
${ }^{7}$ For more information, see https://www.nexteraenergyservices.com/aggregations/massachusetts/cape-lightcompact.

${ }^{8}$ For more information, see https://www.eversource.com/content/docs/default-source/rates-tariffs/ema-capevineyard-rates.pdf?sfvrsn=d77ef362 34.

${ }^{9}$ For more information, see https://www.capelightcompact.org/power-supply/.
} 
Table 6. Modeled Electric Utility Rate

\begin{tabular}{|c|c|}
\hline $\begin{array}{l}\text { Energy charges } \\
\text { Generation charges (NextEra) }\end{array}$ & Units: \$/kWh \\
\hline Generation total: & $\$ 0.09913$ \\
\hline \multicolumn{2}{|l|}{ Delivery charges (Eversource Rate 33) } \\
\hline Distribution charge under 2,300 kWh (majority of sites): & $\$ 0.05500$ \\
\hline Transition charge: & $\$ 0.00002$ \\
\hline Transmission charge: & $\$ 0.02300$ \\
\hline Revenue decoupling charge: & $\$ 0.00058$ \\
\hline Distributed solar charge: & $\$ 0.00100$ \\
\hline Energy efficiency: & $\$ 0.01500$ \\
\hline Renewable energy charge: & $\$ 0.00050$ \\
\hline Delivery total: & $\$ 0.09585$ \\
\hline TOTAL ENERGY CHARGES (SUPPLY + DELIVERY): & $\$ 0.19498$ \\
\hline Demand charges & Units: \$/kW \\
\hline Distribution demand charge - first $10 \mathrm{~kW}$ & --- \\
\hline Distribution demand charge - after $10 \mathrm{~kW}$ & $\$ 5.22$ \\
\hline
\end{tabular}

\subsubsection{Additional Techno-Economic Assumptions}

The economics of adding PV and battery were analyzed under two financing scenarios: direct purchase (agency appropriations) and a traditional energy savings performance contract (ESPC). The financial and economic assumptions and technical assumptions are summarized in Table 7. Technical assumptions are summarized in Table 8.

Table 7. Financial and Economic REopt Assumptions

\begin{tabular}{|c|c|}
\hline $\begin{array}{l}\text { Input } \\
\text { Build year }\end{array}$ & $\begin{array}{l}\text { Assumption } \\
2020\end{array}$ \\
\hline Analysis period & 25 years \\
\hline Ownership model & $\begin{array}{l}\text { (a) Direct purchase by appropriations } \\
\text { (b) ESPC }\end{array}$ \\
\hline Discount rate (nominal) & $\begin{array}{l}\text { 3.1\% for NPS, per the National Institute of } \\
\text { Standards and Technology (NIST) (Lavappa } \\
\text { and Kniefel 2020) } \\
\text { 8.3\% for developer in ESPC scenario, per NREL } \\
\text { Annual Technology Baseline (NREL 2020) }\end{array}$ \\
\hline Inflation rate & $0.1 \%$, per NIST \\
\hline $\begin{array}{l}\text { Electricity cost escalation } \\
\text { rate (nominal) }\end{array}$ & 0.058\%/year, per NIST \\
\hline Net metering limit & $\begin{array}{l}1 \mathrm{MW} \text { (full retail credit); virtual net metering } \\
\text { allowed per Massachusetts state policy } \\
\text { (Mass.gov) }\end{array}$ \\
\hline Incentives & None \\
\hline
\end{tabular}


Table 8. Technical Assumptions

\begin{tabular}{|c|c|c|}
\hline & Input & Assumption \\
\hline \multirow{8}{*}{$\begin{array}{l}\text { a } \\
\frac{1}{0} \\
\text { 은 }\end{array}$} & System type & Fixed tilt systems, ground mount, roof mount, or carport \\
\hline & Technology resource & $\begin{array}{l}\text { Typical meteorological year weather file from the National Solar Radiation } \\
\text { Database - Typical meteorological year3 }\end{array}$ \\
\hline & Area available for PV & Not limited \\
\hline & Installed capacity density & 6 acres/MW-DC \\
\hline & Tilt & $10^{\circ}$ \\
\hline & Azimuth & $180^{\circ}$ (south-facing) \\
\hline & Capital costs & $\begin{array}{l}\text { \$1,600/kW-DC per NREL ATB, } \$ 2,140 / \mathrm{kW}-\mathrm{DC} \text { for carport PV installations } \\
\text { (GTM Research 2017) }\end{array}$ \\
\hline & O\&M costs & $\$ 16 / k W-D C /$ year per NREL ATB \\
\hline \multirow{5}{*}{ 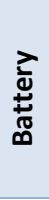 } & Capital costs & $\$ 420 / k W h+\$ 840 / k W$ \\
\hline & Replacement costs & $\$ 200 / \mathrm{kWh}+\$ 410 / \mathrm{kW}$ (single replacement in year 10$)$ \\
\hline & Inverter efficiency & $96 \%$ \\
\hline & Rectifier efficiency & $96 \%$ \\
\hline & DC-DC efficiency & $97.5 \%$ \\
\hline \multirow{8}{*}{ 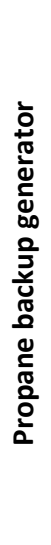 } & Capacity & $45 \mathrm{~kW}$ per CCNS \\
\hline & Fuel type & Propane \\
\hline & Fuel curve & $\begin{array}{l}\text { Based on Generac Model RG045 }{ }^{10} \text { per CCNS: } \\
\qquad \begin{array}{l}25 \% \text { load: } 2.3 \mathrm{gal} / \mathrm{hr} \\
50 \% \text { load: } 4.2 \mathrm{gal} / \mathrm{hr} \\
75 \% \text { load: } 5.9 \mathrm{gal} / \mathrm{hr} \\
100 \% \text { load: } 8.0 \mathrm{gal} / \mathrm{hr}\end{array}\end{array}$ \\
\hline & Fuel cost & $\begin{array}{l}\$ 1.57 / \text { gal per EIA Annual Energy Outlook (commercial propane in New } \\
\text { England region, 2020) }\end{array}$ \\
\hline & Fuel cost escalation rate (nominal) & $2.30 \% /$ year per NIST \\
\hline & On-site fuel storage capacity & $\begin{array}{l}\text { 1,000 gallons per CCNS (analysis assumes no fuel resupply during 7-day grid } \\
\text { outage) }\end{array}$ \\
\hline & Capital costs & None, assume generator already exists \\
\hline & Operations & Only operates during grid outages \\
\hline
\end{tabular}

\subsubsection{Results and Discussion}

\subsubsection{Grid-Connected Results}

First, REopt was used to identify the cost-optimal PV (ground-mount/rooftop and carport) and battery sizes to minimize life cycle electricity costs during normal grid-connected operations; these results are presented in Table 9. Note the net present value listed shows the difference in life cycle costs (life cycle cost savings) between the base case and each potential investment case.

\footnotetext{
${ }^{10}$ For more information, see https://www.generac.com/generaccorporate/media/library/content/allproducts/generators/resi-comm/protector/generac-generators-spec-sheet protector-gaseous-25kw-60kw.pdf.
} 
Table 9. Grid-Connected REopt Results (PV and Battery)

\begin{tabular}{|c|c|c|c|c|c|}
\hline \multirow[t]{2}{*}{ Scenario: } & \multirow{2}{*}{$\begin{array}{c}\text { 0. Base } \\
\text { Case }\end{array}$} & \multicolumn{2}{|c|}{ 1. Direct Purchase } & \multicolumn{2}{|c|}{ 2. Traditional ESPC } \\
\hline & & $\begin{array}{l}\text { a. Ground/ } \\
\text { roof }\end{array}$ & b. Carport & $\begin{array}{l}\text { a. Ground/ } \\
\text { roof }\end{array}$ & b. Carport \\
\hline PV capacity (kW-DC) & ----- & 622 & 622 & 622 & ----- \\
\hline Storage capacity (kW / kWh) & ---- & ---- & ---- & ----- & ---- \\
\hline Total capital cost (after incentives) (\$) & ---- & $\$ 995,200$ & $\$ 1,331,000$ & $\$ 995,200$ & ----- \\
\hline Electricity purchases (kWh) & 680,074 & 667,862 & 667,862 & 667,862 & 680,074 \\
\hline Annual RE generated (kWh) & 0 & 680,074 & 680,074 & 680,074 & 0 \\
\hline Percent RE (\%) & $0 \%$ & $100 \%$ & $100 \%$ & $100 \%$ & $0 \%$ \\
\hline Year 1 energy costs $(\$)$ & $\$ 133,000$ & $\$ 0$ & $\$ 0$ & $\$ 0$ & $\$ 133,000$ \\
\hline Year 1 energy savings (\$) & $\$ 0$ & $\$ 133,000$ & $\$ 133,000$ & $\$ 133,000$ & $\$ 0$ \\
\hline Year 1 demand costs (\$) & $\$ 8,400$ & $\$ 7,100$ & $\$ 7,100$ & $\$ 7,100$ & $\$ 8,400$ \\
\hline Year 1 demand savings (\$) & $\$ 0$ & $\$ 1,300$ & $\$ 1,300$ & $\$ 1,300$ & $\$ 0$ \\
\hline 25-year life cycle costs (\$M) & $\$ 2.21 \mathrm{M}$ & $\$ 1.06 \mathrm{M}$ & $\$ 1.40 \mathrm{M}$ & $\$ 1.71 \mathrm{M}$ & $\$ 2.21 \mathrm{M}$ \\
\hline Net present value (\$M) & ------ & $\$ 1.15 \mathrm{M}$ & $\$ 0.82 M$ & $\$ 0.50 \mathrm{M}$ & $\$ 0$ \\
\hline
\end{tabular}

Results suggest that ground-mount or rooftop solar PV could be cost-effective under either direct purchase or traditional ESPC financing, with a $622-\mathrm{kW}-\mathrm{DC}$ PV system providing $\$ 1.15 \mathrm{M}$ or $\$ 0.50 \mathrm{M}$, depending on financing mechanism, in life cycle cost savings over the 25 -year analysis period. Carport PV appears cost-effective under direct purchase only, with a 622-kW-DC PV system providing $\$ 0.82 \mathrm{M}$. PV cost-effectiveness is driven by the relatively high cost of electricity, particularly the energy charges. In all three scenarios where PV is cost-effective, the system is being sized to generate enough electricity to offset $100 \%$ of the electric load annually. Actual demand charges are likely be higher, and demand charge savings may be lower; the estimates provided here are based on the aggregated load assumption.

Due to the virtual net metering policy and the multisite load aggregation assumed for this highlevel analysis, it appears more cost-effective to export excess PV generation than to install a battery that allows stored excess PV generation to be used directly on-site. However, a battery may be helpful for peak shaving at individual sites to reduce demand charges; additional, more site-specific analysis would be helpful to determine whether potential demand charge savings could make battery cost-effective at some sites. Additionally, battery could help increase site resilience; see next section.

\subsubsection{Resilience Results}

In Analysis 2, the economics of adding PV (ground-mount) and battery were analyzed in conjunction with the economics of utilizing a presumed existing propane generator and fuel storage $\operatorname{tank}^{11}$ (again, under two financing scenarios: direct purchase [agency appropriations] and a traditional ESPC). The focus of this analysis was on resilience benefits for the HQ complex, assuming these systems are sited at the HQ complex. The cost-optimal technology sizes and related results are presented in Table 10.

\footnotetext{
${ }^{11}$ It is assumed that CCNS owns both the generator and fuel tank; no additional costs for these items are included in this analysis.
} 
Table 10. Resilience REopt Results (PV, Battery, and Generator)

\begin{tabular}{|c|c|c|c|c|}
\hline \multirow[t]{2}{*}{ Scenario: } & \multirow{2}{*}{$\begin{array}{l}\text { 0. Base } \\
\text { Case }\end{array}$} & \multicolumn{2}{|c|}{ PV and Battery Only } & \multirow{2}{*}{$\begin{array}{l}\text { PV and Battery } \\
\text { Plus Backup } \\
\text { Generator } \\
\text { Direct Purchase }\end{array}$} \\
\hline & & $\begin{array}{c}\text { Direct } \\
\text { Purchase }\end{array}$ & $\begin{array}{l}\text { Traditional } \\
\text { ESPC }\end{array}$ & \\
\hline PV capacity (kW-DC) & ----- & 600 & 600 & 622 \\
\hline Storage capacity (kW / kWh) & ----- & 24 / 281 & $24 / 281$ & ----- \\
\hline $\begin{array}{l}\text { Backup generator capacity } \\
(\mathrm{kW})\end{array}$ & ----- & ---- & ---- & 45 \\
\hline $\begin{array}{l}\text { Total capital cost (after } \\
\text { incentives) (\$) }\end{array}$ & ----- & $\$ 1,145,380$ & $\$ 1,145,380$ & $\$ 995,200$ \\
\hline Electricity purchases (kWh) & 680,074 & 661,760 & 661,760 & 667,862 \\
\hline $\begin{array}{l}\text { Annual renewable energy } \\
\text { generated (kWh) }\end{array}$ & 0 & 656,345 & 656,345 & 680,074 \\
\hline Percent renewable energy (\%) & $0 \%$ & $97 \%$ & $97 \%$ & $100 \%$ \\
\hline Year 1 energy costs (\$) & $\$ 133,000$ & $\$ 5,000$ & $\$ 9,300$ & $\$ 0$ \\
\hline Year 1 energy savings (\$) & $\$ 0$ & $\$ 128,000$ & $\$ 123,700$ & $\$ 133,000$ \\
\hline Year 1 demand costs $(\$)$ & $\$ 8,400$ & $\$ 6,700$ & $\$ 6,700$ & $\$ 7,100$ \\
\hline Year 1 demand savings (\$) & $\$ 0$ & $\$ 1,700$ & $\$ 1,700$ & $\$ 1,300$ \\
\hline 25-year life cycle costs (\$M) & $\$ 2.21 \mathrm{M}$ & $\$ 1.28 \mathrm{M}$ & $\$ 2.00 \mathrm{M}$ & $\$ 1.06 \mathrm{M}$ \\
\hline Net present value (\$M) & "---- & $\$ 0.93 \mathrm{M}$ & \$0.21 M & \$1.15M \\
\hline
\end{tabular}

The positive net present values of these resilient systems indicate that in addition to providing resilience benefits, the systems are cost-effective. The difference in net present value between these resilient systems and those optimized for purely grid-connected value helps frame the "cost of resilience."

The PV systems are being sized similarly to the grid-connected optimization because the HQ load being assessed for resilience is so much smaller than the overall total load that the system can help offset costs of throughout normal grid-connected operations. If PV and battery are the only technologies available to help survive a grid outage, battery becomes necessary to provide the required resilience. However, if a backup generator is presumed to already exist on-site, it becomes more cost-effective to operate that existing backup generator than purchase a battery.

That said, solar plus storage could extend outage survivability and support resilience for longerduration outages throughout the year if fuel cannot be resupplied. The plot in Figure 14 shows the probability of HQ surviving an outage with $60 \mathrm{~kW}$ of PV available during the outage (of the $600-\mathrm{kW}$ total installed park-wide), $24 \mathrm{~kW} / 281 \mathrm{kWh}$ battery storage, and a $45-\mathrm{kW}$ generator, as opposed to only using the generator to survive the outage. The noted $60-\mathrm{kW}$ PV system is a rough estimate of how much variable generation capacity could help support such a load, with such a battery, in the case of a grid outage, considering electrical engineering and integration factors. Note that a propane-only system can survive nearly all 2-week outages without fuel resupply, but survivability plunges to $0 \%$ at around 2.5 weeks. Propane generator, PV, and battery can survive $\sim 90 \%$ of 3 -week outages without fuel resupply and $\sim 30 \%$ of 4 -week outages, both compared to $0 \%$ survivability with propane generator only. 


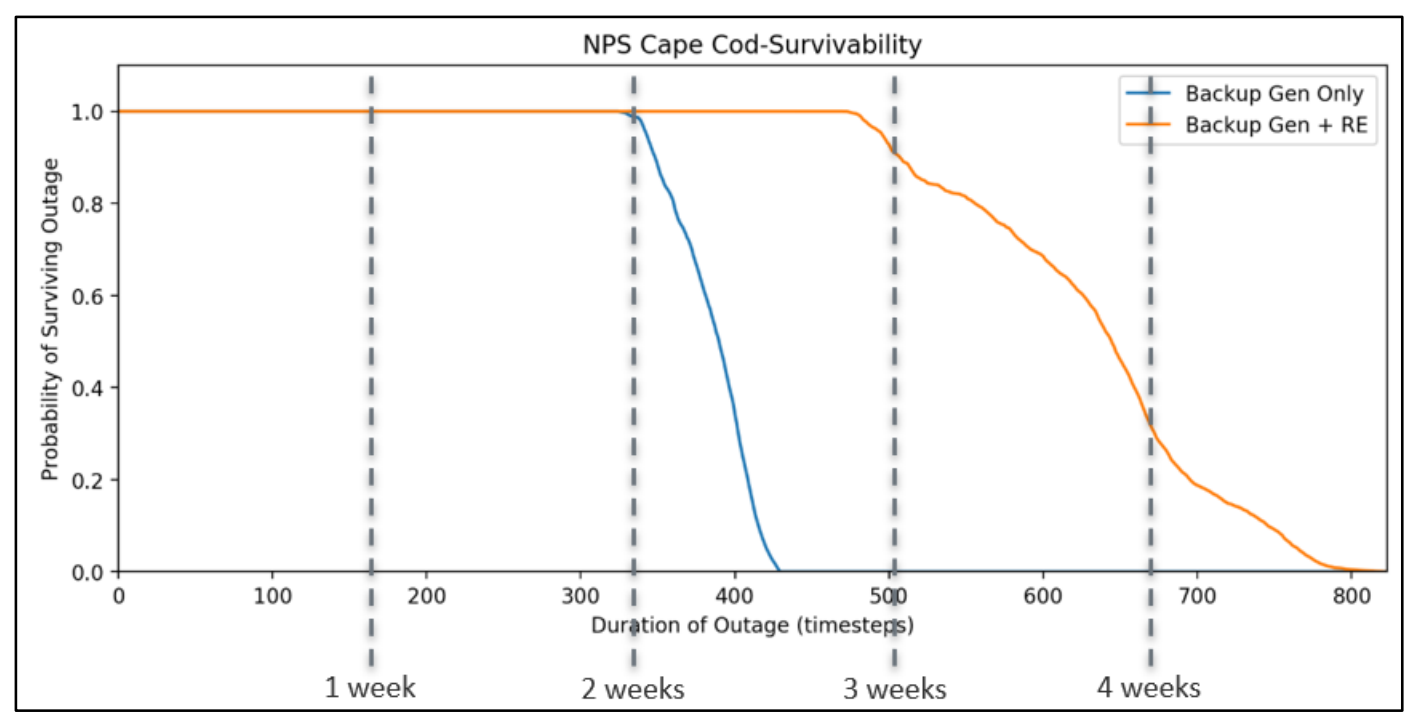

Figure 14. Outage survivability

\subsubsection{Summary Results}

In summary, due to the relatively high cost of electricity, the PV system is primarily being sized for grid-connected operations; specifically, it is being sized to generate electricity equal to the annual electric consumption across all 78 sites. Exact cost savings depend on the financing mechanism; direct purchase by appropriations appears more cost-effective than a traditional ESPC.

Given the aggregated load modeling assumed for this analysis and because virtual net metering is allowed in Massachusetts, battery is not being recommended for grid-connected cost savings. However, additional site-specific screening may identify meters where battery does become costeffective for demand charge savings.

For resilience, solar PV is still being sized for grid-connected operations and could add resilience and extend outage survivability compared to a backup generator only. Solar plus storage can help extend outage survivability as well. 


\subsection{Eversource Outer Cape Battery Storage Project}

Eversource is the electricity utility provider for CCNS and is implementing a large-scale battery project, named the Outer Cape Community Battery Project, that will mitigate the need to build 13 miles of overhead wires on the CCNS.

In recent years, due to increased severity of storms and the unique location, the towns of Provincetown, Truro, and Wellfleet have experienced increased occurrences of power outagesmore than 45,000 customer hours. Traditionally, the increase in outages would be addressed by constructing more overhead wires, but Eversource is striving to increase reliability by building the battery project. The battery project will have a materially lesser footprint and environmental impact than overhead wires. It will be able to provide up to 3 hours of backup power during peak conditions and up to 10 hours during nonpeak times. Provincetown, Truro, and Wellfleet will be able to use the Battery Project to island their electrical systems during an outage to improve reliability by at least $50 \%$.

The battery project is being sited at the transfer station in Provincetown, Massachusetts. On April 2, 2019, the town of Provincetown voted to approve a lease for the project. At the transfer station, Eversource is constructing an approximately 8,550 square foot cape-style building. The proposed building will be approximately 20 feet 4.5 inches tall and has been designed to have minimal impact on the viewscape. CCNS holds a deed restriction on the property where it will be constructed on town land within the park boundary. Park management has consented to the project as a municipal support use in a show of support for the project. 


\subsection{Inventory of CCNS Infrastructure \\ CCNS Infrastructure Summary \\ October 2020}

\section{Energy Infrastructure}

Oil Tanks for Park Administrative Facilities

*Aboveground (AST) Oil Tank Info:

- Penniman: 1 - 275-gallon AST, inside basement

- Nauset Ranger Station: 1 - 275-gallon AST, inside basement

- Fire Cache: 1 - 275-gallon AST, inside new fire cache garage

- Race Point Ranger Station: 1 - 275-gallon AST, inside basement

- Bio Lab: 3 - 275-gallon ASTs, outside lab

- Atlantic Research \& Learning Center (ARLC) classroom and Lab:

- Curatorial: 2 - 275-gallon ASTs, inside building

- Seasonal Housing: 275-gallon aboveground storage tank, inside basement or outside.

*Underground (UST) Oil Tank Info:

- Coast Guard NEED: 1 -1,000-gallon UST, grassy area between parking lot and building

- Headquarters: 1-2,000 UST, left of path looking at rear parking lot

- South District Maintenance: 1 - 2,500-gallon UST, outside auto shop and 1-2,500-gallon UST, outside fire cache office

- North District Maintenance: 1 - 2,500-gallon UST, grassy area to left of LE/Fire cache

- Province Lands Visitor Center: 1-1,000-gallon UST, brushy area near satellite rest room.

\section{Propane Heat}

- ARLC classroom \& ARLC lab — aboveground propane tank, outside buildings.

\section{Natural Gas}

- Salt Pond Visitor Center-service line from Route 6.

\section{Oil or electric heat}

- All remaining heated facilities.

\section{Electric}

- Primarily overhead electric utility (Eversource electric company) and private utility lines

- Eversource electric transmission and distribution system on utility corridor partially adjacent

Solar to the seashore boundary in Wellfleet and South Truro.

- Net-metered solar PV on three buildings: 15-kW array Herring Cove Beach bathhouse, 28$\mathrm{kW}$ array at two buildings with one master meter-Biolab, ARLC Classroom.

Generators - capacity to provide uninterrupted power for 7 days. 1,000-gallon propane tank provided at each location.

- Marconi Water "B” Well-35-kilowatt propane-fired generator rated at 120/208 volts

- Race Point Ranger Station-45-kilowatt propane-fired generator rated at 120/240 volts

- North Atlantic Coastal Laboratory-45-kilowatt propane-fired generator rated at 120/208 volts

- Park HQ - 45-kilowatt propane-fired generator rated at 120/240 volts. 


\section{Transportation Infrastructure}

\section{Transportation Fuel Tanks}

- South District Maintenance: 3,000-gal gas and 1,000-gal diesel—generator to operate in needs to be replaced

- North District Maintenance: 3,000-gal gas (has no generator)

- Little Creek shuttle parking area: 1,000-gal gas (has no generator).

\section{Electric Vehicle Charging Stations}

Level 2 electric vehicle charging stations - 2 at HQ and 1 at North District maintenance for 2 all electric vehicles and 1 hybrid electric vehicle.

Park Fleet: approx. 110 sedans, vans, light- and heavy-duty SUVs and trucks, wrecker, fire trucks and management vehicles, including seasonal beach shuttle trams and trailing cars, plus 12 utility trailers.

\section{Boats and Trailers}

Several skiffs, Boston whalers, and a Jon boat are used by either the Natural Resource Management and Science Division or the Visitor \& Resource Protection Division.

The park also has skiffs with no motors, and kayaks and canoes.

\section{Public Transit Bus Shelters}

- Salt Pond Visitor Center

- HQ.

Marconi Helipad (located behind headquarters)—primarily for medical evacuations.

Waste Infrastructure - park dump truck collection use local trash transfer stations; contracted beach facility waste removal in summer; contract for recyclables and commercial waste dumpsters.

\section{$\underline{\text { Water and Wastewater Infrastructure }}$}

\section{Water systems}

- Marconi water system-100,000-gallon pedosphere (serving HQ, Maintenance, Fire Cache, 10 housing units

- Highlands Center water system-100,000-gallon concrete tank (operated as emergency backup for the Town of Provincetown).

- Salt Pond VC and Nauset Ranger Station facilities and houses in Eastham hooked up to municipal water system; more facilities will be hooked up when the system is expanded.

* Critical park facility

Public water systems:

Salt Pond Visitor Center-approx. 3/4M gallons/yr.

Coast Guard Station NEED building-513K gallons/year

Nauset Light Beach restrooms - 33 to $43 \mathrm{~K}$ gallons/yr.

Marconi Water (has back-up generator power at B-well now) - $1.38 \mathrm{M}$ gallons/yr.

Other park public water systems: Hemenway restroom, Doane Rock picnic area restroom, Truro

NEED, Highland Light, Head of the Meadow, Pilgrim Heights 
Town provides water in Provincetown and we are billed-Race Point Ranger Station*, Herring Cove Beach, Province Lands Visitor Center*, North District Maintenance, houses, restroom.

Fire hydrants

Town of Provincetown water system hydrants (North District Maintenance*, Province Lands Visitor Center*, Provincetown Municipal Airport, Race Point Beach, and Head of Meadow Beach)

Highlands Center, Truro

Wellfleet Trash Transfer Station hydrants at Herring River/Old County Road

Town of Wellfleet water system hydrants at Marconi Station entrance road at Route 6 near Marconi $\mathrm{HQ}^{*}$ and South District Maintenance* (Marconi Entrance station Hydrant is CCNS from Marconi Water tower)

New Town of Eastham hydrant system serving Salt Pond Visitor Center* and Nauset Ranger Station* along park western boundary

Eastham Coast Guard NEED — static hydrant — over 5,000-gallon tank

Town of Orleans at Nauset Beach Inn, Orleans.

Fire Suppression Systems

Race Point Ranger Station-Provincetown*

Old Harbor Lifesaving Station-Provincetown

ARLC Classroom-Truro

ARLC Lab-Truro (out of operation)

Highland Lighthouse-Truro

Fire Cache Building-Wellfleet*

Salt Pond Visitor Center-Eastham*

Salt Pond Comfort Station-Eastham

Coast Guard NEED-Eastham

Penniman House-Eastham

Atwood Higgins house — not maintained.

\section{Large septic systems}

- At critical facilities above - central system at HQ, fire cache, and maintenance

- Highlands Center

- Five ocean beach bathhouses*.

*The sixth beach facility, Herring Cove Beach, is hooked up to the Provincetown wastewater system

\section{$\underline{\text { IT/Communications Infrastructure }}$}

Data/Telephone Communications

CCNS consists of 5 primary Local Area Networks:

All servers and VOIP/network equipment are equipment are connected to UPS units.

Marconi Complex, consisting of headquarters, maintenance offices and shops, and the fire cache, connects to the NPS Wide Area Network (WAN) via Comcast cable internet service. Telephone communications are provided by a VOIP system that exit the park on a Verizon PRI circuit (copper).

Salt Pond Visitor Center connects to the NPS WAN via Comcast Cable internet service and an L2L device. Telephone communications are provided by a VOIP system via Verizon POTS (copper) lines.

Nauset Ranger Station connects to the NPS WAN via Comcast Cable internet service and an L2L device. Telephone communications are provided by a VOIP system via Verizon POTS (copper) lines. 
North Atlantic Coast Lab (NACL or biolab) connects to the NPS WAN via two vBNS (T1) circuits (copper). Telephone communications are provided by a VOIP system via Verizon POTS (copper) lines.

Race Point Ranger Station connects to the NPS WAN via one vBNS (T1) circuits (copper). The LAN extends to the ORV office and Old Harbor Life Saving Station via ark fiber cabling. Telephone communications are provided by a VOIP system via Verizon POTS (copper) lines.

During the summer season, six fee booths connect to the NPS WAN via cellular and an L2L device and Province Lands Visitor Center connects to the NPS WAN via Verizon DSL connection and an L2L device.

\section{Utility Providers}

Comcast Xfinity is local cable internet provider.

Open Cape Corporation fiber optic runs up utility corridor in Wellfleet, but they do not currently serve park facilities.

Verizon telephone.

Emergency 911 call boxes at 6 ocean beaches ( 5 cellular, 1 satellite)

\section{Satellite phones}

Lifeguards, 2 shift supervisors and dispatch have 9 satellite phones in case radio system unavailable for beach safety.

Natural Resources staff also have on beaches for shorebird patrols in summer in case of emergency.

\section{Park Radio System Infrastructure}

CCNS has a law enforcement radio system and an operations radio system. The law enforcement radio system comprises one repeater and two receivers. Both the law enforcement and operations radio systems have two channels. Channel 1 on our radio systems is law enforcement-direct and broadcasts locally (within line of sight.) Channel 2 will transmit over the law enforcement repeater to all of the Outer Cape and to Boston Telecommunications Operations Center (TOC) via a Radio over Internet Protocol (RoIP). On the operations system, Channel 3 is the operations direct channel and broadcasts locally (within line of sight.) Channel 4 will transmit over the operations repeater to all of the Outer Cape.

\section{Law Enforcement Radio System (Closed system)}

- The 24-hourTOC@ Boston National Historical Park

- Motorola Quantar repeater@ Marconi Water Tower:

- Receiver Locations:

- Province Lands Visitor Center (1)

- Coast Guard Beach in Eastham (1)

○ Radio over Internet Protocol (RoIP) system equipment @ park headquarters in computer room

- Digital Interface Unit @ park headquarters in computer room:

- This unit converts the digital signal to analog to be sent to Boston TOC.

- Comparators housed at HQ:

- The comparator broadcasts the strongest of the signals received over the repeaters. 


\section{Operations Radio System (Open system)}

- Motorola Quantar repeater @ trailer under the Truro tower behind the Public Safety Building - Receiver Locations:

- Marconi water tower base (1) --(Antenna is on top of tower)

- Coaster Guard Beach in Eastham (1)

- (When the Marconi to Truro FDDA circuit is down, both the CG and Marconi Ops receivers will not function.)

- Spare repeater antenna house in the base of the water tower.

\section{Radio System Frequencies (14)}

When broadcasting on local channels, the greater the power the radio is using, the further the signal will be broadcast. The handheld radio will not broadcast as far as the mobile unit in a vehicle; the handheld unit is approx. 5 watts, while the vehicles are usually 100 watts.

Law Enforcement Radio System: Currently, there is equipment for a third receiver that would go in the trailer under the Truro tower. The law enforcement receiver is currently not set up there because Verizon has been unable to get their circuit functional to transmit the signal to the repeater in Wellfleet. The LE receiver has separate FDDA circuits that go from the receiver sites to the Marconi water tower, where the LE repeater then broadcasts the transmission.

\section{Radio System Equipment at Park Headquarters Computer Room}

The radio equipment in the park headquarters computer room includes two comparators (one for the law enforcement channel and one for the Ops channel), a Digital Interface Unit, and a Zitron unit. Verizon has five FDDA circuit boxes mounted in the computer room.

\section{Radio System Equipment at the Province Lands Visitor Center} One LE receiver is located at the Province Lands Visitor Center. One antenna is located inside the building on the highest part of the visitor center ceiling. Verizon has their lines coming into the basement of the visitor center and the box that has the circuit number for the law enforcement radio receiver is clearly marked.

\section{Radio System Equipment at the Truro Tower Trailer}

The Motorola Quantar operations repeater. The Verizon circuit comes into the basement of the Public Safety Building. Town owned phone lines then run between the Public Safety Building and the equipment in the trailer. The operations repeater antenna is located on the Truro Tower. It is located halfway up the tower on the east facing side of the tower.

\section{Radio System Equipment at the Marconi Water Tower}

One Motorola Quantar law enforcement repeater. One operations receiver. One UPS battery backup with one external battery sleeve. The antenna is located on the top of the water tower.

\section{Radio System Equipment at Coast Guard Beach Bathhouse in Eastham}

One law enforcement receiver located in the custodial room in the southwest corner of the bathhouse. One operations receiver (same location as law enforcement receiver). One antenna is located on the south-facing gable end of the bathhouse.

FDDA Circuits: We have four FDDA circuits that transmit radio broadcasts from radio receivers to the repeaters. We also have the RoIP connection that transmits from the law enforcement repeater to our dispatch at Boston TOC. 
Bos/Toc: Boston National Historical Park, Charlestown Navy Yard, $19^{\text {th }} 1^{\text {st }}$ Ave. Bldg. 109, Boston, MA

Coast Guard Beach Station: 1020 Doane Rd, Eastham, MA

Water Tower: 99 Marconi Site Rd, Wellfleet, MA

\section{Miscellaneous Radio Information}

Motorola XTS5000 Portable Radios with 7.5-inch VHF Wideband Antenna

Models-I, II, III (all models used by V\&RP)

52 Portable Radios purchased between 1999-2005

Two Multi-Battery Tri-analyzer/charger Systems-Housed at the Race Point Ranger Station.

\section{Law Enforcement Vehicle Mobile Radio Units}

Motorola Spectra Digital Radios

Two models: W-4 and W-5. One has knobs, the other has buttons. 


\title{
5.5 Site Visit Agenda
}

\author{
NPS/NREL Operations Resilience Workshop \\ Wed. November 20, 2019 \\ CCNS Headquarters \\ 99 Marconi Site Road, Wellfleet, MA \\ --Wednesday Agenda--
}

9 a.m.-10 a.m.-Welcome, Introductions, \& Coffee-Meet Green Team to Review Project

- Greg Guibert, Senior Resilience Analyst | NREL Strategic Energy Analysis Center, NREL

- Alison Holm, Project Leader with the Integrated Decision Support Group in the Integrated Applications Center, NREL

- Amanda L. Babson, Ph.D., Coastal Landscape Adaptation Coordinator, NPS Northeast Region

10 a.m.-CCNS Sites Tour and Solar Assessments*

- Lauren McKean, Park Planner, CCNS

- Travis Lavenski, Park Planning Assistant, AmeriCorps Cape Cod

- Salt Pond Visitor Center

- Little Creek Staging Area*

- Coast Guard Beach

- Nauset Light Beach

- Marconi Beach*

- CCNS Headquarters, maintenance, water tower, helipad, and fire cache*

- BlackfishCreek@State Route6low-lying roadvulnerability

\section{2:30 p.m.-Lunch at Bookstore Restaurant in Wellfleet}

\section{1:30 p.m.-Continue CCNS Sites Tour and Solar Assessments}

- Herring River/Great Island

- Ballston Beach coastal overwash

- Highlands Center + North Atlantic Research Lab*

- Highland Light

- Head of the Meadow Beach*

- Province Lands Visitor Center*

- Herring Cove Beach

- Race Point Beach*

4 p.m.-Wrap-Up

4:15 p.m.-Prep for Workshop and Adjourn 
Solar Assessments* for PV or PV carport

Park Attendees for Green Team Meeting

Brian Carlstrom, Superintendent

Lauren McKean, Park Planner

Travis Lavenski, Assistant Park Planner, AmeriCorps Cape Cod

Stephen Smith, Plant Ecologist

Erik Anderson, Park Mechanic

Jenna Sammartino, Interpretive Ranger

Brandon Flint, Administrative Officer

Ross Cox, Facility Management Software System Specialist

Seth DiGiacomo, Park Ranger

\section{NPS/NREL Operations Resilience Workshop \\ Thurs. November 21, 2019 \\ CCNS Headquarters \\ 99 Marconi Site Road, Wellfleet, MA \\ --Thursday Agenda-}

\section{9 a.m. Begin Workshop: Introductions}

Monta Baskerville and park (and any others) will call in to conference line 866-817-6971, passcode 7939375\# (leader 372868\#)

Welcome and Introductions-Superintendent Brian Carlstrom

Park Introduction-Lauren McKean and Travis Lavenski (also get \# for pizza order for lunch)

\section{9:10 a.m. NREL Introduction}

Greg Guibert, Senior Resilience Analyst, NREL Strategic Energy Analysis Center, NREL

Alison Holm, Project Leader with the Integrated Decision Support Group in the Integrated Applications Center

\section{9:30 a.m.-12:30 p.m. Facilitated topics with interactive exercises (1 hour each)}

- Identify CCNS's top hazards, threats, and vulnerabilities and understand the linkages between them, particularly as it relates to your critical infrastructure.

- Document existing efforts and plans that might address those challenges and catalogue any existing gaps.

- Discuss drivers of change at the site and better understand how those might constrain any solutions.

\section{2:30 p.m. Bag lunch or pizza at HQ}

1 p.m. Resume Workshop, if needed

2 p.m. Adjourn 


\section{Leads/Attendees}

NREL

Greg Guibert, Senior Resilience Analyst | NREL Strategic Energy Analysis Center, Alison Holm, Project Leader with the Integrated Decision Support Group in the Integrated Applications Center

Washington Office

Monta Baskerville, Energy Program Manager

NPS Northeast Region

Amanda L. Babson, PhD, Coastal Landscape Adaptation Coordinator

\section{CCNS Attendees}

Brian Carlstrom, Superintendent

Leslie Reynolds, Deputy Superintendent/former Chief Ranger

Kathy Tevyaw, former Deputy Superintendent

Lauren McKean, Park Planner

Travis Lavenski, AmeriCorps Cape Cod Park Planning Assistant

Karst Hoogeboom, Chief of Facilities and Maintenance

John DeFoe, Roads, Trails and Grounds Supervisor

Bill Burke, Branch Chief of Cultural Resources

Richard Murphy, Water and Wastewater Systems Manager

Mark Adams, GIS Specialist

Mike DeMarco, Park Electrician

Jesse Olbrich, Facility Management Software System Assistant

Dave Crary, Fire Management Officer

\section{Contributors in Addition to Workshop Attendees:}

Adam Baghetti, IT Specialist

Tristan Jilson, AmeriCorps Cape Cod - NS Planning Assistant

Catherine Miles, Executive Assistant 


\subsection{Risk Matrix}

The Risk Matrix utilized in this analysis is embedded here:

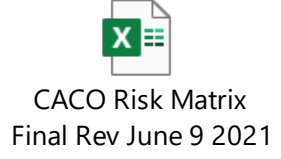




\section{References}

Anderson, K., E. Hotchkiss, L. Myers, and S. Stout. 2019. "Energy Resilience Assessment Methodology." Renewable Energy.

Beavers, R.L., A.L. Babson, and C.A. Schupp [eds.]. 2016. Coastal Adaptation Strategies Handbook 2016. Coastal Adaptation Strategies Handbook. NPS 999/134090. National Park Service: Washington, D.C.

Caffrey, Maria, Rebecca L. Beavers, and Cat Hawkins Hoffman. 2018. Sea Level Rise and Storm Surge Projections for the National Park Service. Washington, D.C.: National Park Service. Natural Resource Report Series NPS/NRSS/NRR - 2018/1648. https://www.coastalreview.org/wp-content/uploads/2018/08/2018-NPS-Sea-Level-ChangeStorm-Surge-Report-508Compliant.pdf.

DOE (U.S. Department of Energy). "National Parks Initiative.” Partnerships \& Projects. https://cleancities.energy.gov/national-parks.

DOE. "Resilience Roadmap.” https://www.nrel.gov/resilience-planning-roadmap/.

GTM Research. 2017. “U.S. PV System Pricing H2 2017: Forecasts and Breakdowns.”

Lavappa, Priya D., and Joshua D. Kniefel. 2020. "Energy Price Indices and Discount Factors for Life-Cycle Cost Analysis | 2020 Annual Supplement to NIST Handbook 135.” 85-3273-35. Gaithersburg, MD: NIST. https://www.nist.gov/publications/energy-price-indices-and-discountfactors-life-cycle-cost-analysis-150-2020-annual.

Mass.gov. “Net Metering Guide.” https://www.mass.gov/guides/net-metering-guide.

NPS (National Park Service). 2016. Coastal Adaptation Strategies Handbook. https://www.adaptationclearinghouse.org/resources/national-park-service-coastal-adaptationstrategies-handbook.html.

NPS. "Coastal Facilities Vulnerability Assessments." Climate Change. Last modified November 19, 2020. https://www.nps.gov/subjects/climatechange/vulnerabilityandadaptation.htm.

NPS. "Frequently Asked Questions.” About Us. Last modified January 21, 2021. https://www.nps.gov/aboutus/faqs.htm.

NPS. "Great American Outdoors Act.” Legislative and Congressional Affairs. Last modified February 2, 2021. https://www.nps.gov/subjects/legal/great-american-outdoors-act.htm.

NPS. 2018. Sea Level Rise and Storm Surge Projections for the National Park Service. https://www.coastalreview.org/wp-content/uploads/2018/08/2018-NPS-Sea-Level-ChangeStorm-Surge-Report-508Compliant.pdf.

NREL (National Renewable Energy Laboratory). 2020. “Annual Technology Baseline.” https://atb.nrel.gov/. 
Stout, S. R., Lee, N., Cox, S. L., Elsworth, J., and Leisch, J. 2019. Power Sector Resilience Planning Guidebook: A Self-Guided Reference for Practitioners. NREL/TP-7A40-73489.

Golden, CO: NREL. https://www.nrel.gov/docs/fy20osti/74983.pdf. 